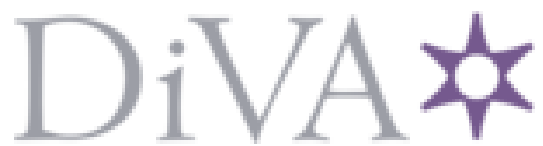

http://www.diva-portal.org

This is the published version of a paper published in Wood and Fiber Science.

Citation for the original published paper (version of record):

Florisson, S., Muszynski, L., Vessby, J. (2021)

Analaysis of hygro-mechanical behavior of wood in bending

Wood and Fiber Science, 53(1): 27-47

https://doi.org/10.22382/wfs-2021-04

Access to the published version may require subscription.

N.B. When citing this work, cite the original published paper.

Permanent link to this version:

http://urn.kb.se/resolve?urn=urn:nbn:se:lnu:diva-10160o 


\title{
ANALYSIS OF HYGRO-MECHANICAL BEHAVIOR OF WOOD IN BENDING ${ }^{1}$
}

\author{
S. Florisson* $\dagger$ \\ Doctoral Candidate \\ Department of Building Technology \\ Linnaeus University \\ Växjö, Sweden \\ E-mail: sara.florisson@lnu.se \\ L. Muszyński† \\ Professor \\ Wood Science and Engineering \\ Oregon State University \\ Corvallis, OR \\ E-mail: lech.muszynski@oregonstate.edu \\ J. Vessby $\dagger$ \\ Senior Lecturer \\ Department of Engineering and Chemical Sciences \\ Karlstad University \\ Karlstad, Sweden \\ E-mail: johan.vessby@kau.se
}

(Received October 2020)

\begin{abstract}
The empirical test developed as validation for a new beam element model that can account for both mechanical and environmental load action in finite element analysis is presented. The testing protocol allows for the identification and analysis of contributing deflection components in bending under varying MC conditions, including mechano-sorption. The components of deflection in the shear-free span of a four-point bending test and their responses to varying moisture are evaluated with an analytical procedure. The experiment was conducted on clear, straight-grained sapwood and heartwood specimens of Norway spruce (Picea abies) $\left(30 \times 15 \times 640 \mathrm{~mm}^{3}\right)$. The program consisted of three phases: 1$)$ long-term (LT) experiments under constant temperature of $60^{\circ} \mathrm{C}$ and RH cycles between $40 \%$ and $\left.80 \%, 2\right)$ a short-term static experiment to determine the variation in the sample set and the load level of the LT experiment on end-matched specimens, and 3) creep tests at $60^{\circ} \mathrm{C}$ and constant humidity at either $40 \%$ or $80 \%$ to determine the effect of moisture on the viscoelastic creep. Mass changes and hygro-expansion measured on matched specimens were used in the analytical method. Constitutive models used for describing the material-level response to loads and moisture changes were applied to the shear-free segment of the specimens disregarding actual moisture gradients and fiber orientation inside the test specimens. A successful identification of each deflection component and isolation of mechano-sorption component was accomplished. In the 90 da of testing, the dominant component of the total deflection was the elastic component, followed by the mechano-sorptive component. Creep was found to be nonnegligible and important in the correct description of mechano-sorption. The effect of moisture on the viscoelastic behavior showed most important during loading and first stages of decreasing deflection rate phase.
\end{abstract}

Keywords: Bending, solid wood, Norway spruce, creep, experimental methodology, mechano-sorption, viscoelasticity.

\footnotetext{
* Corresponding author

†WST member

${ }^{1}$ The copyright of this article is retained by the authors.
} 


\section{INTRODUCTION}

When wood is subjected simultaneously to stress and MC changes below the FSP, the mechanosorptive phenomenon may be observed as an additional deformation that cannot be explained by a simple superposition of elastic deformation, free shrinkage or swelling, and creep at constant MC (Muszyński et al 2005). Mechano-sorption is a second-order phenomenon, which means that the mechano-sorptive deformation cannot be measured directly, as it is always accompanied by viscoelastic and free hygro-expansion deformation. To properly isolate the mechano-sorptive deformation, these components must be measured independently in reference tests on matched specimens and subtracted from the total deformation of the specimens tested in changing climatic conditions (Bengtsson 1999; Muszyński et al 2005; Hering et al 2012). This is rarely carried out in published empirical studies (Morlier 1994; Muszyński et al 2006; Lagaňa et al 2011). When properly isolated, the mechano-sorptive deformation appears somewhat similar to viscoelastic creep. Under high stress levels and long series of moisture cycles, three stages of deformation may be observed, which correspond to the three stages of viscoelastic creep: a primary stage, with a decreasing deflection rate, followed by a secondary stage, with a constant deflection rate, and, potentially, a tertiary stage, characterized by an increasing deflection rate that can lead to failure (Armstrong and Christensen 1961; Hearmon and Paton 1964; Hunt 1989; Hunt 1999). Thanks to this analogy, the first two stages may be adequately described by phenomenological models resembling simple spring-dashpot models, where the time domain needed to describe viscoelastic behavior is replaced with the cumulative MC change defined as follows:

$$
v=\int_{0}^{t}|\dot{w}| \mathrm{d} t .
$$

Here, $\dot{w}$ is momentary MC change rate in the time domain. In reference to these models, an analogue to the Newton dashpot, proposed independently by Rybarczyk (1973) and Ranta-Maunus (1975) may be presented as follows:

$$
\varepsilon_{m s}=\alpha \sigma v,
$$

where $\alpha$ is a parameter analogue to an inverse of viscosity and $\sigma$ is a constant stress value. An analogue to a Kelvin element is obtained by adding a parallel spring parameter $E_{m s}$, as proposed independently by Rybarczyk (1973) and Salin (1992):

$$
\varepsilon_{m s}=\frac{\sigma}{E_{m s}}\left(1-e^{-\alpha E_{m s} v}\right) .
$$

Since the first reports in 1960s (Armstrong and Christensen 1961), mechano-sorption has been extensively researched. The progress made in the state of knowledge is summarized in Holzer et al (1988), Morlier (1994), Hunt (1999), Hanhijärvi (2000) and Muszyński et al (2005). However, Morlier (1994), Hunt (1999), and Muszyński et al (2005) pointed out that the experimental programs used in published studies show a lot of variation and often a superficial analysis of results. Typically, the total deflection between the bearing supports is recorded, which includes effects of shear, and indentation under loads and over bearing supports (Brancheriau et al 2002). When the separation of deflection components is attempted, many authors only subtracted the effect of shrinkage and swelling, whereas in general, the viscoelastic creep is neglected (Hering and Niemz 2012). To properly isolate the mechano-sorptive effect, Muszyński et al (2005) and Muszyński et al (2006) have proposed an experimental methodology based on the commonly accepted concept that the total strain $\varepsilon_{t}$ may be considered a separable superposition of an elastic $\varepsilon_{e}$ component, hygroexpansion $\varepsilon_{h}$, creep component $\varepsilon_{c}$, and mechanosorptive $\varepsilon_{m s}$ component, as in Eq 4.

$$
\varepsilon_{t}=\varepsilon_{e}+\varepsilon_{h}+\varepsilon_{c}+\varepsilon_{m s}
$$

This methodology was then applied to tests on specimens of red spruce loaded in tension parallel to the grain with a load level equal to $70 \%$ of the greenstate ultimate tensile stress, subjected to a constant temperature of $21^{\circ} \mathrm{C}$ and $18 \mathrm{RH}$ cycles between 30 and $98 \%$. Subsequently, Lagaňa et al (2011) proved that mechano-sorptive characteristics measured on small clear wood specimens in tension and 
compression along the grain can be successfully used in predicting complex behavior of beams subjected to loads and varying climatic conditions.

Recently, a beam element model that can account for both mechanical and environmental load action was developed (Ormarsson and Dahlblom 2013; Ormarsson and Steinnes 2014; Ormarsson and Gíslason 2016). This model builds on the essential feature of the beam theory proposed by Bernoulli, such that the plane section normal to the beam axis remains plane and normal to the beam axis during deformation (Ottosen and Petersson 1992). This means that $\varepsilon_{t}$ as described by $\mathrm{Eq} 4$ has to vary linearly over the cross section, whereas the strain portions $\varepsilon_{e}, \varepsilon_{h}, \varepsilon_{c}$, and $\varepsilon_{m s}$ can vary arbitrarily (Ormarsson and Dahlblom 2013). In the three-dimensional plane, the input parameters to the beam model are the compliance matrix, which contains the elastic and shear moduli, the vector $\gamma$ of hygro-expansion coefficients, the mechanosorption matrix $\boldsymbol{m}$ including the mechanosorption parameter $\alpha$, the spring parameter of Kelvin creep model $\phi_{\sigma}^{n}$, and the dashpot viscosity of Kelvin creep model $\tau_{n}$, where $n$ indicates the amount of the Kelvin model modules arranged in series. The transformation from the local coordinate system $(l, r, t)$, which accounts for the fiber orientation, to the global coordinate system $(x, y, z)$ is carried out by means of transformation matrices. These matrices are also used to transform the threedimensional notation of $\varepsilon_{h}, \varepsilon_{c}$, and $\varepsilon_{m s}$ to a suitable notation for the beam theory. As output, the beam model generates the bending moment, deflection diagrams, and the cross-section stress distribution. The model accounts for two-dimensional moisture gradients within the beam elements (Ormarsson and Gíslason 2016). Compared with the solid finite element models used to simulate moisture-induced strains, the beam model is much more computationally efficient and can therefore be applied on structural-level modeling. However, the beam model still needs an experimental validation to determine its accuracy and to identify its potential limitations.

Therefore, the primary motivation for this work is the calibration of the beam model with empirical data from carefully controlled bending tests in variable climatic conditions. A meaningful validation requires that the experimental procedure allows for clear separation of the contributing components of the total deflection, as listed in $\mathrm{Eq}$ 4 , so that the contribution made by mechanosorption to the total deflection of the beam can be isolated. Although such procedures have been successfully demonstrated for tension and compression (Muszyński et al 2006), it is a serious challenge in case of bending in varying climatic conditions, where nonuniform stress distribution coincides with nonuniform development of moisture gradients within the same specimen's volume (Muszyński et al 2005). To the authors' knowledge, no successful attempt for such procedure allowing clear separation of the deflection components in beams had been reported at the time of the inception of the project presented in this article. The purpose of the current article is to describe the experimental methodology, analytical procedures, and outcomes of tests on small clear wood specimens subjected to bending in varying climatic conditions, and the validation of the beam model will be described in a separate publication.

The specific objectives of this experimental study were 1) to develop the experimental setup and analytical procedure applied to separate components of the total deflection measured on beams subjected to bending in varying climate; 2) to determine the expected variation of the material properties in the material used for the tests described in objective 1), as represented by strength and stiffness of specimens extracted from various positions in the harvested logs; 3 ) to analyze the effect of moisture on the viscoelastic creep to enhance the analytical procedure; 4) to determine the hygro-expansion coefficients of the test material; and 5) to fit the isolated mechano-sorption deflection curve with a suitable model.

\section{EXPERIMENTAL PROGRAM}

The testing protocol was designed based on the assumption that the total deflection of beams subjected to sustained load under varying climatic conditions is separable into individual components. The mechano-sorptive deflection 
$u_{m s}$ was isolated from the total deflection $u_{t}$ by subtracting the elastic component $u_{e}$, creep $u_{c}$, and hygro-expansion $u_{h}$, determined with reference tests (Eq 5).

$$
u_{m s}=u_{t}-\left(u_{e}+u_{c}+u_{h}\right)
$$

The main part of the experimental program was of a long-term four-point bending test conducted under varying climatic conditions on sapwood and heartwood specimens of Norway spruce. A four-point bending test was used to obtain deflection data from the shear-free section to exclude shear and indentation under loads and over supports. The tests were conducted in a constant temperature of $60^{\circ} \mathrm{C}$ and nine $10-\mathrm{d}$ humidity cycles varying between equal 5 -d stages at $40 \%$ and $80 \% \mathrm{RH}$. Before testing, the specimens were preconditioned in the test chamber at $60^{\circ} \mathrm{C}$ and $40 \%$ RH. These conditions were kept through the first $5 \mathrm{~d}$. This procedure allowed recording of the immediate elastic deflection $u_{e}$ and the initial viscoelastic creep trajectory, before the RH cycles were launched. The specimens were unloaded in the conditions similar to those at the beginning of the test and left unloaded for two additional RH cycles to measure the recovery of deflection.

The reference tests were designed to isolate the mechano-sorptive component of deflection:

1. Creep tests in constant climate at $40 \%$ and $80 \%$ $\mathrm{RH}$ were used to determine the effect of moisture on the viscoelastic response.

2. Short-term (ST) static tests (at an MC close to the FSP) were conducted on end-matched specimens to estimate the variation in the modulus of rupture $f_{b}$ and the elastic modulus $E$ in the test material, to provide context for the variability of elastic deflection $u_{e}$ values determined from loading and unloading procedures in the main test, and to determine the stress level for the long-term (LT) tests in reference to $f_{b}$.

3. The mass of unloaded matched specimens was recorded to approximate the average $\mathrm{MC}$ of the loaded specimens, neglecting the moisture gradients within the specimens.

4. The hygro-expansion of the depth of an unloaded matched specimen was monitored to estimate the cross section's dimensional change of the loaded specimens and their effect on the modulus of inertia.

The outline of the experimental program with an overview of the type of tests performed, the load levels, the provenience, the number of specimens used, the deflection components measured, and expected types of results is presented in Table 1. The following sections are concerned with the description and the treatment of the specimens, presentation of the test setup and procedures, and the discussion of the analytical approach and its limitations.

\section{Materials and Specimen Fabrication}

All test specimens were fabricated from three logs of Norway spruce related to 60-yr-old trees acquired from a private stand named Engaholms skogar located near Lyngsåsa in Southern Sweden. The logs were harvested in winter time and kept in frozen state before and after further processing at Asa försökspark. The cutting scheme followed the conical shape and annual ring pattern in the logs but could not eliminate spiral grain. Eight sapwood and eight heartwood specimens (25th and 13th annual ring, respectively) were extracted from each $1.5-\mathrm{m} \log$. The distinction between sapwood and heartwood was made on the green-state MC right after felling the tree. The specimens were marked according to their position within the log, related to a specific wind direction (Fig 1). The 1.5-m rectangular sections extracted from the logs were subsequently cut in two equal segments to obtain endmatched specimen pairs marked for static and LT tests (Fig 1).

After cutting, the specimens covered in plastic sheets to minimize drying were transported to Linnaeus University's laboratory and stored in a freezer until the final cutting and planing to $30 \mathrm{~mm} \times 15 \mathrm{~mm} \times 640 \mathrm{~mm}($ depth $\times$ width $\times$ length) while in frozen state. The span-todepth ratio over 18 allowed the mitigation of the effect of shear deformation to below $6 \%$ of the total deflection measured on the full span 
Table 1. Outline of the experimental plan.

\begin{tabular}{|c|c|c|c|c|c|c|c|c|c|c|c|}
\hline \multirow[b]{2}{*}{ Data type } & \multirow[b]{2}{*}{ Load levels $^{* * *}$} & \multirow[b]{2}{*}{ Specimen labels } & \multirow{2}{*}{$\frac{\text { Number of specimens }}{\mathrm{swd}_{\mathrm{hwd}} *}$} & \multicolumn{4}{|c|}{ Deflection components } & \multicolumn{4}{|c|}{ Material parameters } \\
\hline & & & & $u_{e}$ & $u_{c}$ & $u_{h}$ & $u_{m s}$ & $E$ & $\phi_{\sigma}$ & $\tau$ & $f_{b}$ \\
\hline $\begin{array}{l}\text { Main (LT) }(40-80 \% \\
\left.\quad \text { RH } 60^{\circ} \mathrm{C}\right)\end{array}$ & & $\mathrm{T} 1-2$ & & & & & & & & & \\
\hline $\begin{array}{c}\text { Deflection } \\
\text { Reference }(\mathrm{LT})(40- \\
\left.80 \% \mathrm{RH} 60^{\circ} \mathrm{C}\right)\end{array}$ & $34 \%$ & NN/SS/EE & $3 / 3$ & $x$ & $x$ & & $x$ & $x$ & $\times$ & $x$ & \\
\hline $\begin{array}{l}\text { Hygro-expansion } \\
\text { Mass change }\end{array}$ & $\begin{array}{l}0 \% \\
0 \%\end{array}$ & WW & $1 / 1$ & & & $\times$ & & & & & \\
\hline $\begin{array}{l}\text { ST }\left(98 \% \text { RH } 21^{\circ} \mathrm{C}\right) \\
\text { Creep }\left(40 \% \text { RH } 60^{\circ} \mathrm{C}\right)\end{array}$ & ultimate & $\begin{array}{l}\text { T1-3, } \mathrm{T} 1-3, \mathrm{~T} 2-4 \\
\mathrm{~T} 1-3\end{array}$ & $24 / 24$ & & & & & $x$ & & & $\times$ \\
\hline $\begin{array}{l}\text { Deflection } \\
\text { Mass }\end{array}$ & $\begin{array}{l}34 \% \\
0 \%\end{array}$ & $\begin{array}{l}\text { NN/SS/EE } \\
\text { WW }\end{array}$ & $\begin{array}{l}3 / 3 \\
1 / 1\end{array}$ & $x$ & $x$ & & & $x$ & $\times$ & $x$ & \\
\hline Creep $\left(80 \%\right.$ RH $\left.60^{\circ} \mathrm{C}\right)$ & & $\mathrm{T} 1-3$ & & & & & & & & & \\
\hline $\begin{array}{l}\text { Deflection } \\
\text { Mass }\end{array}$ & $\begin{array}{l}34 \% \\
0 \%\end{array}$ & $\begin{array}{l}\text { NW/SE/NE } \\
\text { SW }\end{array}$ & $\begin{array}{l}3 / 3 \\
1 / 1\end{array}$ & $x$ & $x$ & & & $x$ & $\times$ & $x$ & \\
\hline
\end{tabular}

*Sapwood (swd) and heartwood (hwd).

**Percentage of the mean $(\mu) f_{b}$ at $30 \%$ MC

of the beam. The specific dimensions were dictated by the constraints of the loading setup inside the climate chamber.

The specimen's ID system, as shown in Fig 2, marked the tree (T1 or T2), the $\log (2-4)$, the specimen's orientation in the log (NN, NE, EE, $\mathrm{SE}, \mathrm{SS}, \mathrm{SW}, \mathrm{WW}, \mathrm{NW}$ ), the radial position (sapwood or heartwood: $s$ or $h$ ), and their designation to the LT or static tests (LT or ST). Logs labeled T1-2, T1-3, and T2-4 resulted in 24 pairs of sapwood specimens and 24 pairs of heartwood specimens. The 48 crown-end specimens were used in the static tests, whereas the root-end specimens were used in the LT and creep tests. The summary of specimen assignment to specific

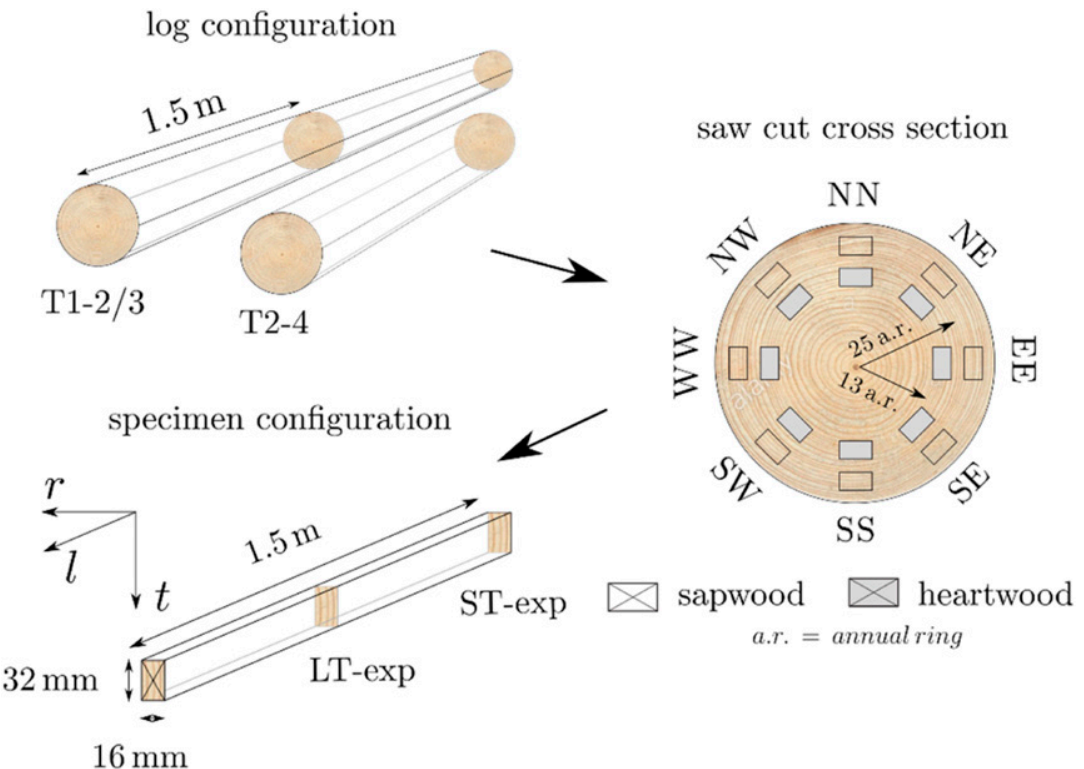

Figure 1. Diagram illustrating processing of the material samples from tree trunks, through logs, toward paired bending specimens. 


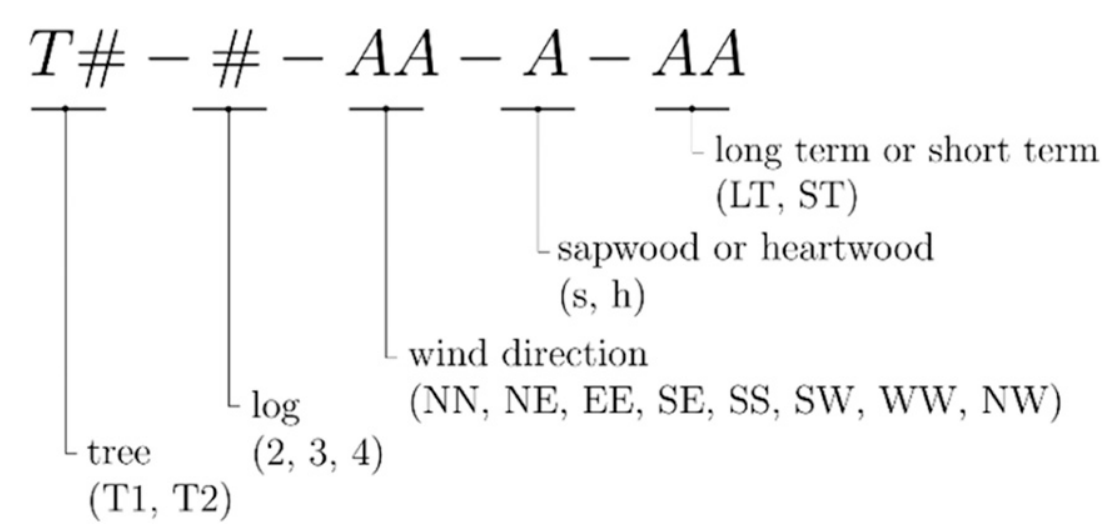

Figure 2. Identification method for specimens.

tests is summarized in the fourth column of Table 1.

\section{Specimen Treatment and Storage}

Specimens for LT and creep tests. Both ends of the frozen LT-specimens were sealed with a silicone sealant (Sikaflex ${ }^{\circledR}$ AT-connection, Sika AG, Baar, Switzerland) to prevent moisture gradients along the grains. Five days before testing, the specimens were conditioned inside the climate chamber in the climate used for testing (for creep tests in steady conditions) or in the climate related to the initial RH phase (for LT tests conducted in varying conditions): $60^{\circ} \mathrm{C}$ and $40 \% \mathrm{RH}(\approx 7.2 \% \mathrm{EMC})$ or $60^{\circ} \mathrm{C}$ and $80 \% \mathrm{RH}$ ( $\approx 15 \%$ EMC) At the end of each test, the MC of all specimens was determined by using the ovendry method (EN13183-1 2003).

Specimens for static tests. The sample set of 24 sapwood and 24 heartwood specimens was tested in static bending at an MC above the FSP to obtain the lower limit values of $E$ and $f_{b}$, meant to understand the contribution of individual logs and specific positions within the $\operatorname{logs}$ to the variability of the results of the LT tests, and to determine the load level used in the LT and creep tests. To prevent sorption hysteresis, the specimens were dried from green state to an MC close to the FSP in five sealed plastic boxes equipped with fans, salt boxes, and heaters (IGLOO IMR2/ A, Amiga AB, Vara, Sweden) for a period of
$110 \mathrm{~d}$ before testing. A potassium sulfate solution was used to maintain high humidity. For sapwood specimens, the conditioning regimen was $95 \%$ $\mathrm{RH}$ at $70^{\circ} \mathrm{C}$ for the first 40 da and $98 \% \mathrm{RH}$ at $21^{\circ} \mathrm{C}$ for the rest of the conditioning period. Heartwood specimens were conditioned at $98 \%$ $\mathrm{RH}$ and $21^{\circ} \mathrm{C}$ all the time. The progress of the drying was monitored by recording the weight of the specimens every $5 \mathrm{~d}$ on average using a $\pm 0.001 \mathrm{~g}$ Sartorius LP620S analytical balance (Sartorius AB, Göttingen, Germany). The RH and temperature inside these boxes was monitored with Testo 635 sensors $( \pm 0.7 \%$ of the measured temperature value and $\pm 1.8 \%$ of the $\mathrm{RH}$ value). In these conditions, the specimens dried very slowly from green condition to $30 \%$ $\mathrm{MC}$, until the daily mass differences were less than $1 \%$, an MC still above 26\% FSP reported for Norway spruce (Bratasz et al 2012). To prevent mold or rot, the specimens were cleaned with ethanol on a daily basis.

\section{Test Setup}

LT tests. The LT tests with varying climate and creep tests at constant humidity were conducted in a Vötsch VCR 4033/S climate chamber (Vötsch Industrietchnik GmbH, Balingen, Germany). A custom-made loading fixture was used to test three specimens simultaneously in bending (Fig 3). The fixture consisted of a steel test frame, movable lateral supports (Fig 3[a]), mechanical supports consisting of a roller and a pinned 
connection type (Fig 3[b] and [c]), an aluminum loading rig (Fig 3[d]), and dead loads. The loading fixture was held up by struts attached to the interior of the climate chamber. The climate inside the chamber was regulated by a water bath with a temperature range between $10^{\circ} \mathrm{C}$ and $90^{\circ} \mathrm{C}$ and an $\mathrm{RH}$ range between $30 \%$ and $80 \%$. During the tests, the climate in the chamber was monitored by three external pin-type temperature $\left( \pm 0.3^{\circ} \mathrm{C}\right)$ and humidity $( \pm 1.8 \% \mathrm{RH})$ sensors (SHT75 Sensirion, Stäfa, Switzerland) placed in the upper left back, upper right back, and lower right front of the climate chamber. A comparison with the recording made by the sensors built in the climate chamber showed a difference in temperature below $0.1 \%$ and a difference in $\mathrm{RH}$ within $5 \%$.

The deflection over a length of $160 \mathrm{~mm}$ shear-free section of the beams (Figs 4-3/4 and $u_{l}$ in Fig 4[a] [b]) was measured by linear variable differential transformers (LVDT) (HBM WI, Darmstadt, Germany) with a measuring range of $10 \mathrm{~mm}$ $( \pm 1 \mu \mathrm{m})$ mounted in a yoke that was attached to the beam at the neutral axis (Figs 3[d] and 4-4). The tip of the LVDT was loosely pressed under an L-shaped element that was also placed in the neutral axis at midspan (Figs 3[d] and 4-5). Full span deflection was measured as well, but the measurements are not used in this article.
Static tests. An $\mathrm{MTS}^{\circledR}-810$ universal testing machine (UTM: MTS ${ }^{\circledR}$ systems Corporation, Eden Prairie, MN) was used to perform the static bending tests. The UTM was equipped with a $100 \mathrm{kN} \pm 2 \mathrm{~N}$ load cell and a custom-made fourpoint bending steel testing fixture, as illustrated in Fig 4b. The specimen was supported on two rollers at a 595-mm span, anchored on a base steel beam nested in the UTM. The load was transferred through an aluminum load evener pivoted at the upper grip of the UTM and then to the beam through two steel rollers at a heart distance of $190 \mathrm{~mm}$ (Fig 4[b]). The force between the rollers and the specimen was distributed by steel bearing plates with a 5-mm thickness, a 16-mm width, and a 55-mm length. The deflection over a length of $160 \mathrm{~mm}$ shear-free section of the beams was measured with an LVDT with an accuracy of $\pm 0.01 \mathrm{~mm}$ attached to the neutral axes at midspan using an L-shaped element (see close-up Fig 4 [b]). The deflection over the full span was also measured, but not included in this article. The same setup was also used to determine $E$ and $f_{b}$ after the specimens were tested in the LT tests and additional creep tests.

Measurement of MC. The moisture changes in specimens tested in the climate chamber were estimated based on changes in mass of an
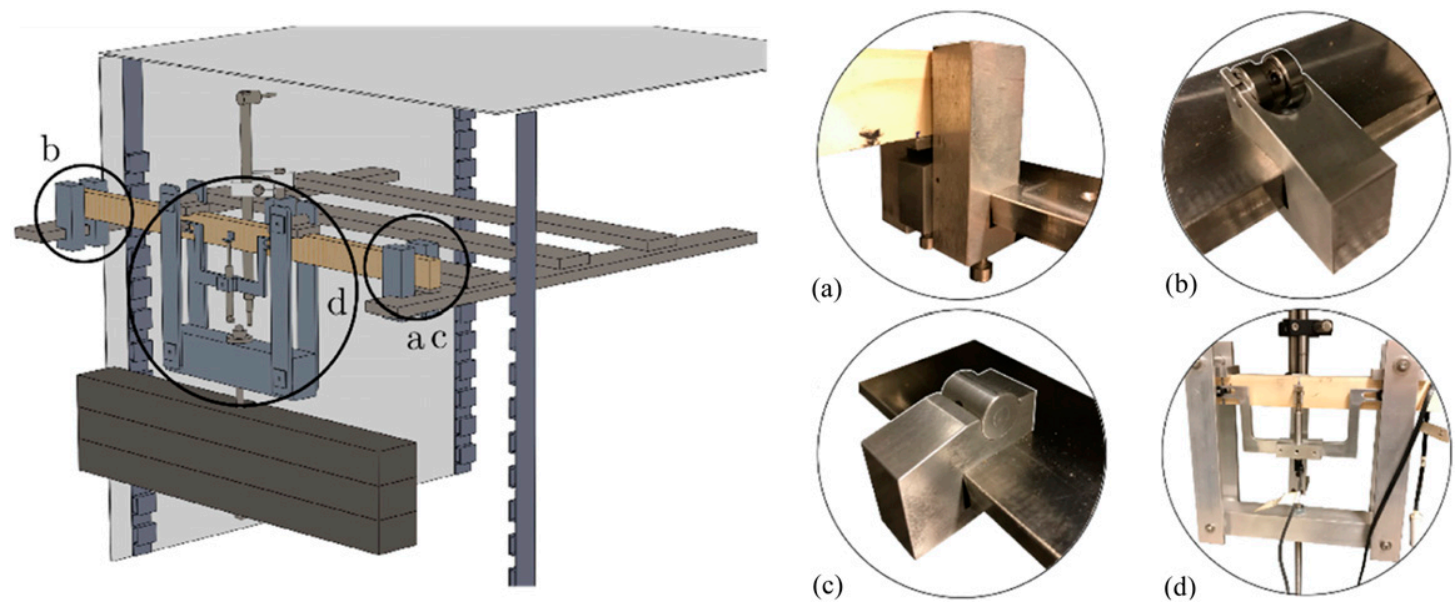

Figure 3. Rendering of the setup for long-term tests under varying and constant climate conditions, including details of the (a) lateral support, (b) roller support, (c) pinned support, and (d) displacement transducers and aluminum loading rig. 

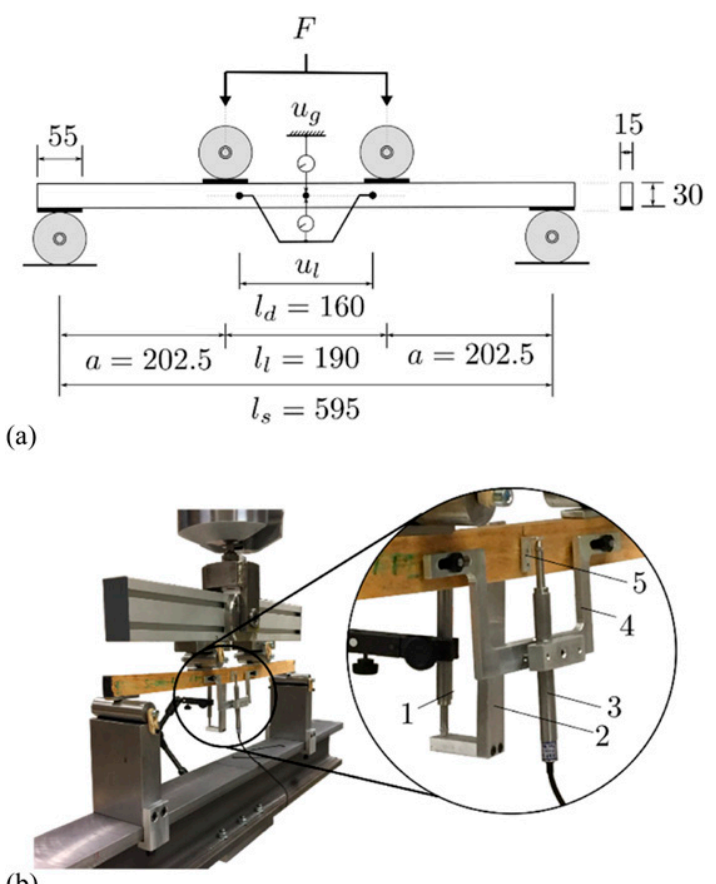

(b)

Figure 4. (a) Schematic representation of the static setup and (b) photos, where1) is the LVDT measuring over the span of the specimen, 2) is the L-shaped element to support the LVDT and locate it in the neutral axis of the specimen, 3) is the LVDT measuring in the shear-free area of the specimen, 4) is the gauge used to position the LVDT, and 5) is the L-shaped element to place the LVDT at the neutral axis of the specimen.

unloaded reference specimen monitored with a waterproof Vibra CJ $820 \mathrm{CE} \pm 0.01 \mathrm{~g}$ balance with a $820 \mathrm{~g}$ range (Lidén Weighing $\mathrm{AB}$, Kungälv, Sweden, see Fig 5[b]) placed inside a
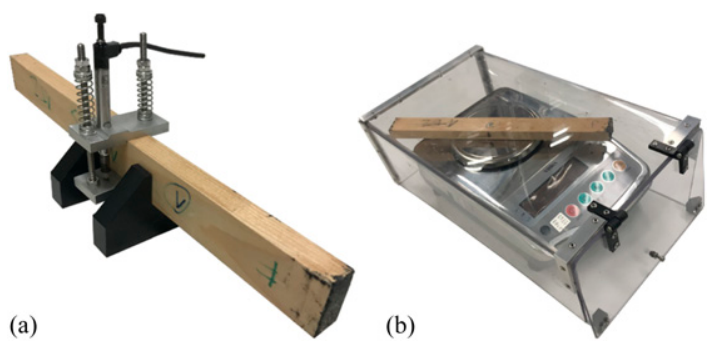

Figure 5. Additional equipment to the climate chamber, where (a) is the fixture to measure shrinkage and swelling over the depth of the specimen and (b) is a waterproof electronic scale including plastic coverage to measure the change in mass. ventilated plastic box to avoid the interference of the internal air current. At the end of the test, the $\mathrm{MC}$ of each specimens was determined with the oven-dry method (EN 13183-1 2003).

Measurement of free hygro-expansion. The free hygro-expansion $u_{h}$ in specimens tested in the climate chamber was estimated based on measurements of the depth of a matched unloaded specimen using a custom fixture shown in Fig 5[a]. An HBM WI displacement transducer was used with a measuring range of $10 \mathrm{~mm}( \pm 1 \mu \mathrm{m})$.

Data acquisition and storage. Signals from the humidity sensors and the transducers were collected with a QuantumX box (HBM), connected to a DAQ application Catman (HBM), whereas the signal from the scale was sent to a separate custom DAQ application by Saab AB (Sweden). The two systems were not synchronized and had different time stamps.

\section{Testing Procedures}

LT experiment and creep tests. The specimens tested in the climate chamber were loaded manually with calibrated dead loads in increments of $100 \mathrm{~N}$ on a rod attached to the loading rig, which added $13 \mathrm{~N}$ to the total load. For this procedure, the testing frame was partially slid out of the chamber using a custom supporting frame. A total load of $413 \mathrm{~N}$ was used for the sapwood specimens and $313 \mathrm{~N}$ for the heartwood specimens (Fig 6[a]), calibrated to achieve a target nominal bending stress below $40 \%$ of $f_{b}$ at the FSP measured in the static tests, to prevent early failure of specimens. The related nominal bending stress for sapwood specimens was 18.6 MPa (bearing stress at the supports of $0.25 \mathrm{MPa}$ ) and $14.1 \mathrm{MPa}$ for the heartwood specimens (bearing stress 0.19 $\mathrm{MPa})$. It is important to keep in mind that the stress values change with changing geometry during $\mathrm{RH}$ cycles.

Both the LT tests and creep tests have been conducted at a constant temperature of $60^{\circ} \mathrm{C}$ (Fig $6[\mathrm{~b}])$ to accelerate the development of deformations compared with lower temperature. The 

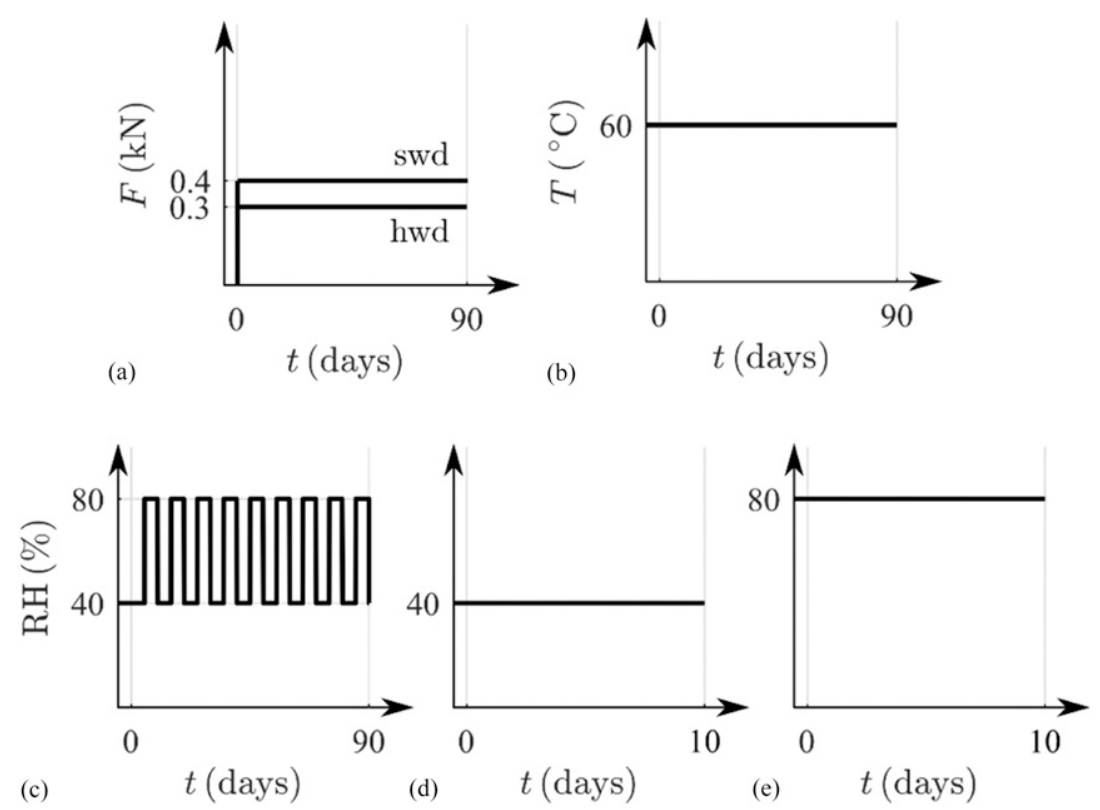

Figure 6. Climate and load schedules for sapwood (swd) and heartwood (hwd) specimens used in the long-term experiment and creep tests: (a) load $(F)$, (b) temperature (T), (c) RH schedule for LT experiment, (d) RH schedule for creep tests at $40 \%$ $\mathrm{RH}$, and (e) RH schedule for creep tests at $80 \% \mathrm{RH}$.

creep and mechano-sorptive response rates are higher at elevated temperatures, as shown by Carlsson and Thunell (1975), Bodig and Jayne (1982), and Castera (1989). The RH schedule used in the main LT test illustrated in Fig 6(c) consisted of nine 10-d cycles: $5 \mathrm{~d}$ at $40 \%$ RH and $5 \mathrm{~d}$ at $80 \%$ RH. The RH schedule used in the creep tests is presented in Fig 6(d) and (e). Specimens EE, NN, and SS were tested for $10 \mathrm{~d}$ at a constant $\mathrm{RH}$ of $40 \%$, and specimens NE, SE, and NW were tested at a constant RH of $80 \%$.

The LT tests were continued until a constant deformation rate was confirmed by $R^{2} \geq 0.95$ in a linear regression analysis on deflection values obtained at the end of the four consecutive RH phases of both the adsorption and desorption curves. At the end of the tests, specimens were unloaded and the elastic recovery was measured. After that, the humidity cycles continued with no load for 25 more days. Once the recovery phase was completed, the specimens were removed from the loading fixture and stored in a constant climate of $60^{\circ} \mathrm{C}$ and $40 \% \mathrm{RH}$ until tested in static bending to obtain the residual $E$ and $f_{b}$. The static tests were performed at a room temperature of $21^{\circ} \mathrm{C}$ and an $\mathrm{RH}$ of $35 \%(\mathrm{EMC} \approx 6.9 \%)$. At the end of the test, the MC of each specimens was determined with the oven-dry method (EN 13183-1 2003).

Static tests. To minimize drying between mounting and testing $( \pm 5 \mathrm{~min})$, the test specimens were pulled one at a time from the climate boxes located next to the UTM. The specimens were loaded with a displacement rate of $1 \mathrm{~mm} / \mathrm{s}$. The specimens were first preloaded to $300 \mathrm{~N}$, unloaded to $50 \mathrm{~N}$, and then loaded to failure. Load and displacement data were collected at a sampling rate of $5 \mathrm{~Hz}$. At the end of the test, the $\mathrm{MC}$ of each specimens was determined with the oven-dry method.

\section{Analysis of Results}

Tests with cyclic climate changes. To resolve the components of the total deflection curve $u_{t}$ measured in the shear-free section of the beam span, an analytical procedure was developed. 
This procedure uses the description of $u_{t}$ presented in Eq 6, and Eqs 7-9 to describe $u_{e}, u_{c}$, and $u_{m s}$, respectively. In the formulation of $u_{e}$ according to Eq 7 (EN 408 2012), the effects of hygro-expansion are only included to describe the variation in the modulus of inertia of the crosssection during cyclic moisture changes. It can be safely assumed that the hygro-expansion along the beam axis does not affect the deflection in the plane of loading. However, $u_{h}$ is added to the measured $h$ at $40 \% \mathrm{RH}$ and $60^{\circ} \mathrm{C}$, and $0.33 u_{h}$ to the measured $b$ at $40 \% \mathrm{RH}$ and $60^{\circ} \mathrm{C}$ (Bengtsson 2001).

$$
\begin{gathered}
u_{t}=u_{e}+u_{c}+u_{m s} \\
u_{e}=\frac{3 F a l_{l}^{2}}{4 E(w) b(w) h^{3}(w)} \\
u_{c}=u_{e}^{*} \sum_{n=1}^{2} \phi_{\sigma}^{n}(w)\left(1-e^{-t / \tau_{n}}\right) \\
u_{m s}(v)=u_{e}^{*}\left(\frac{1}{E_{m s}}\left(1-e^{-v \alpha_{1} E_{m s}}\right)+v \alpha_{2}\right)
\end{gathered}
$$

A 2-module Kelvin model is used to describe $u_{c}$ for all specimens (see $\mathrm{Eq} \mathrm{8).} \mathrm{The} \mathrm{model} \mathrm{is}$ modified such that the elastic deflection right after loading $u_{e}^{*}$ is used to scale $u_{c}$, which is an analogue to the description of $\varepsilon_{c}$ in the beam element model, as described in the introduction. To describe $u_{m s}$, the analogues of the Newton and Kelvin models presented by Eqs 2 and 3 are combined in Eq 9. The deflection is scaled using the same elastic deflection right after loading $u_{e}^{*}$. Eq 9 is best analyzed in the cumulative moisture change or $v$-domain (rather than in the time domain). Because the cumulative MC change adds absolute values of all minuscule values of the recorded $\mathrm{MC}$ change, it is sensitive to noise in the MC signal. In fact, the level of noise was high enough to substantially affect the total length of the recorded cumulative moisture change $v$. The noise in the MC data was therefore removed by moving the average each $14 \mathrm{~min}$.

Linear expressions (10-12) were used to describe the effect of MC $w$ below the FSP $\left(w_{a}\right)$ on the viscoelastic model parameters and to describe the shift in the FSP $\left(w_{f}\right)$ at elevated temperature. In Eq $10, T_{0}$ is a reference temperature of $20^{\circ} \mathrm{C}$ and $T$ the test temperature of $60^{\circ} \mathrm{C}$. The term $\psi_{f T}$ describes the shift in the FSP due to a unit increment in temperature. The value for $w_{f}$ for Norway spruce at reference temperature is $26 \%$ (Bratasz et al 2012) and holds a value of $\Psi_{f T}$ was assumed $0.0033^{\circ} \mathrm{C}^{-1}$ (Dinwoodie 1981). The expression 11 for $E$ is based on experimental work carried out by Dinwoodie (1981). The reference value $E_{0}$ is unique for each specimen and determined from the instantaneous elastic deflection in the total deflection curve obtained in the LT tests under cyclic climate. The term $Y_{w 0}$ indicates the change in $E_{0}$ due to unit MC increment, and holds a value of $21000 \mathrm{MPa}$ (Keunecke et al 2007). The reference values $\phi_{\sigma 0}^{n}$ were unique for each specimen and obtained with a fit on the creep deflection data monitored in the first $5 \mathrm{~d}$ until the first climate cycle, whereas the term $\chi_{w 0}$ that describes the change in $\phi_{\sigma}$ due to unit MC increment was determined from the reference creep tests. The complete analytical procedure was implemented in MATLAB $^{\circledR}$ (MathWorks, Natick, MA).

$$
\begin{gathered}
w_{f}=0.26\left(1+\Psi_{f T}\left(T_{0}-T\right)\right) \\
E=E_{0}+Y_{w 0}\left(w_{f}-w_{a}\right) \\
\phi_{\sigma}^{n}=\phi_{\sigma 0}^{n}+\chi_{w 0}^{n}\left(w_{f}-w_{a}\right)
\end{gathered}
$$

Creep at constant climate. The creep tests at constant climate were used to obtain $\chi_{w 0}^{n}$ for both the sapwood and heartwood sample sets (see $\mathrm{Eq}$ 12). The creep deflection was isolated from the total deflection curve by subtracting $u_{e}^{*}$. The individual and the average values of $u_{c}$ fitted Eq 8. To obtain $\chi_{w 0}$ for each of the two Kelvin modules, a linear relation was assumed between the obtained average values for $\phi_{\sigma}$ at $40 \%$ and $80 \%$ RH with Eq 12.

The procedure used to analyze the effect of moisture on $u_{c}$ for each specimen tested in the LT experiment is visualized in Fig 7. In this figure, the expected creep curves at a constant RH levels of $40 \%$ and $80 \%$ are drawn. The MC influences the deflection rate $\mathrm{d} u_{c} / \mathrm{d} t$ during either of the two $\mathrm{RH}$ 
phases of the climate cycle (Engelund and Salmen 2012; Hering and Niemz 2012). Instead of simulating a gradual change in the deflection rate following the MC change in the specimens, a simplified but conservative assumption was made that the creep rate changes immediately with EMC corresponding the $40 \%$ or $80 \% \mathrm{RH}$ phase of the cycle. The effect of the moisture cycles on $u_{c}$ is estimated by a summation of deflection increments $\Delta u_{c}$ at $40 \%$ and $80 \% \mathrm{RH}$ for each of the 9 cycles analyzed in the LT test.

Static tests. The ST test was used to determine reference $E$ and $f_{b}$ based on Eqs 13 and 14, respectively

$$
\begin{aligned}
& E=\frac{3}{4} \frac{a l_{d}^{2}}{b h^{3}} \frac{\Delta F}{\Delta u_{l}} \\
& f_{b}=3 F a / b h^{2},
\end{aligned}
$$

where $\Delta F / \Delta u_{l}$ is the slope of the linear section of the load-displacement curve measured in the shearfree section of the beam over a displacement range $\Delta u_{l}$ between 0.1 and $0.25 \mathrm{~mm}$. The slope $\Delta F / \Delta u_{l}$

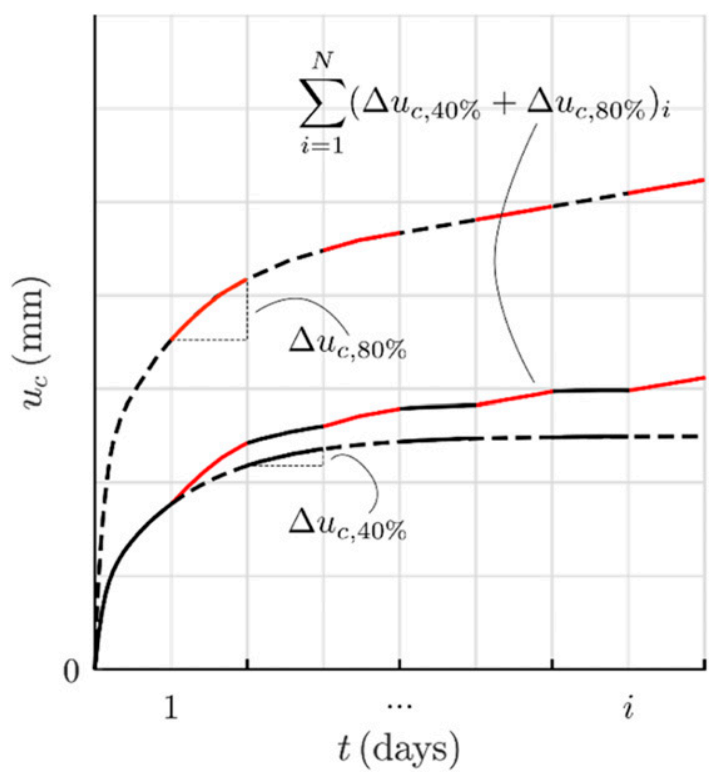

Figure 7. Procedure used to analyze the increase in creep deflection $u_{c}$ due to systematic changes in $\mathrm{RH}$ between $40 \%$ and $80 \%$, where $\Delta u_{c}$ is the increase in deflection after each respective $\mathrm{RH}$ phase and $i$ indicates the amount of RH cycles. was estimated using a linear regression analysis. A satisfying result was obtained, when a coefficient of correlation larger than 0.99 was found (EN 408 2012). The mean values for $E, f_{b}$, and $w$ were determined for sapwood and heartwood specimens harvested from different positions of the logs and, separately, for pooled data for all positions.

Hygro-expansion. The hygro-expansion coefficient $\gamma$ is needed in the beam model to describe the strain related to shrinkage and swelling of the cross section $\varepsilon_{h}$ and the resulting changes in the section modulus of inertia. The $\gamma$ for each $\mathrm{RH}$ cycle was determined for both the sapwood and heartwood specimens using Eqs 15 and 16

$$
\begin{gathered}
\varepsilon_{h}=\frac{h_{80}-h_{40}}{h_{80}} \\
\gamma=\frac{\varepsilon_{h}}{w_{80}-w_{40}},
\end{gathered}
$$

where $\varepsilon_{h}$ is determined using the depth of the specimen at an EMC corresponding to $80 \% \mathrm{RH}, h_{80}$, and at an EMC corresponding to $40 \% \mathrm{RH}, h_{40}$. The slight curvature of the annual rings in the cross-section was neglected.

\section{RESULTS AND DISCUSSION}

The following section presents the primary results obtained with the procedures described in Section 2. To isolate the mechano-sorptive deformations in the LT tests with variable climate conditions, it is necessary to subtract the other components of the total deflection based on measurements obtained from the reference and creep tests, as described in Eq 6. Therefore, first, the results from the static tests, creep tests, mass measurements, and hygroexpansion measurements are discussed, and the resulting mechano-sorptive deflection curves and the results of fitting the mechano-sorption deflection model are presented last.

\section{Static Tests}

In Table 2 , the mean values for $w, f_{b}$, and $E$ are collected for the all-sapwood and all-heartwood sample sets as well as for the individual wind 
Table 2. Mean $\mu$ for MC $w$ measured at the end of the experiment, the modulus of rupture $f_{b}$, and the elastic modulus $E$ for either the whole sapwood (swd) or heartwood (hwd) sample set or individual wind directions

\begin{tabular}{|c|c|c|c|c|c|c|c|c|c|c|c|c|c|}
\hline \multirow{2}{*}{\multicolumn{2}{|c|}{$\begin{array}{l}\text { Specimen } \\
\text { location } \\
\text { in the log }\end{array}$}} & \multicolumn{4}{|c|}{$w(\%)$} & \multicolumn{4}{|c|}{$f_{b}(\mathrm{MPa})$} & \multicolumn{4}{|c|}{$E(\mathrm{GPa})$} \\
\hline & & \multirow{2}{*}{$\frac{\#}{3}$} & \multirow{2}{*}{$\frac{\text { swd }}{30.3}$} & \multirow{2}{*}{$\frac{\#}{3}$} & \multirow{2}{*}{$\begin{array}{l}\text { hwd } \\
30.1\end{array}$} & \multirow{2}{*}{$\frac{\#}{3}$} & \multirow{2}{*}{$\frac{\text { swd }}{45.6}$} & \multirow{2}{*}{$\frac{\#}{3}$} & \multirow{2}{*}{$\begin{array}{c}\text { hwd } \\
36.1\end{array}$} & \multirow{2}{*}{$\frac{\#}{3}$} & \multirow{2}{*}{$\frac{\text { swd }}{10.8}$} & \multirow{2}{*}{$\frac{\#}{3}$} & \multirow{2}{*}{$\begin{array}{c}\text { hwd } \\
7.76\end{array}$} \\
\hline $\mathrm{NN}$ & $\mu$ & & & & & & & & & & & & \\
\hline $\mathrm{EE}$ & $\mu$ & 2 & 31.2 & 3 & 30.0 & 1 & 44.8 & 2 & 39.0 & 1 & 9.0 & 2 & 8.32 \\
\hline SS & $\mu$ & 3 & 30.1 & 3 & 29.9 & 3 & 46.8 & 2 & 31.4 & 3 & 11.9 & 2 & 7.99 \\
\hline WW & $\mu$ & 3 & 30.5 & 3 & 29.7 & 2 & 50.1 & 3 & 37.4 & 3 & 11.9 & 3 & 8.35 \\
\hline $\mathrm{NE}$ & $\mu$ & 3 & 30.0 & 3 & 29.7 & 3 & 46.3 & 3 & 35.1 & 2 & 11.7 & 3 & 7.25 \\
\hline SE & $\mu$ & 3 & 30.6 & 3 & 30.0 & 1 & 41.3 & 3 & 31.9 & 2 & 11.9 & 3 & 7.71 \\
\hline SW & $\mu$ & 3 & 30.4 & 3 & 29.8 & 3 & 47.9 & 3 & 35.7 & 3 & 13.1 & 3 & 9.00 \\
\hline NW & $\mu$ & 3 & 30.3 & 3 & 33.6 & 3 & 49.2 & 3 & 33.0 & 3 & 12.9 & 3 & 8.98 \\
\hline All & $\mu$ & 23 & 30.3 & 24 & 30.4 & 19 & 47.0 & 22 & 34.9 & 20 & 11.9 & 22 & 8.2 \\
\hline
\end{tabular}

directions. The results found for $w$ confirm that specimens were at $30 \% \mathrm{MC}$ during testing. For $f_{b}$, a mean value of $47 \mathrm{MPa}$ for the all sapwood sets and $35 \mathrm{MPa}$ for the all heartwood sets were found. The sapwood values exceed those published in the FLP Wood Handbook for clear wood specimens in green state for several spruce species, which where between 42 and $32 \mathrm{MPa}$ (Wood Handbook 2010). The same is seen for $E$, where the mean values for sapwood and heartwood were 11.9 and $8.2 \mathrm{GPa}$, respectively, whereas the reported values by the FLP Wood Handbook were between 9.5 and 7.1 GPa (Wood Handbook 2010).

The largest difference in $E$ was found between the all-sapwood and all-heartwood data sets (Fig 8). The differences in characteristics observed in specimens harvested from sapwood and heartwood zones may be attributed to the content of juvenile wood; however, we were not able to determine the content of juvenile wood directly, and we cannot make such conclusions with definite or even measurable margin of confidence. Minor differences in $E$ between mean values for the wind direction from $\mathrm{NN}$ to NW were found in the sapwood and heartwood sample sets (11.9-13.1/7.7-9.0 GPa).

Based on the mean $f_{b}$ for the all sapwood and all heartwood sample sets, a load level of $34 \%$ of the ultimate value was chosen for both the sapwood and heartwood specimens used in the LT tests under varying and constant climate conditions. However, $f_{b}$ measured in the static tests on specimens subjected to the LT tests indicated that the actual load levels were between 15 and 30\%.

\section{Creep Tests}

The results of the creep tests at $40 \%$ and $80 \% \mathrm{RH}$ are presented in Fig 9, along with the individual
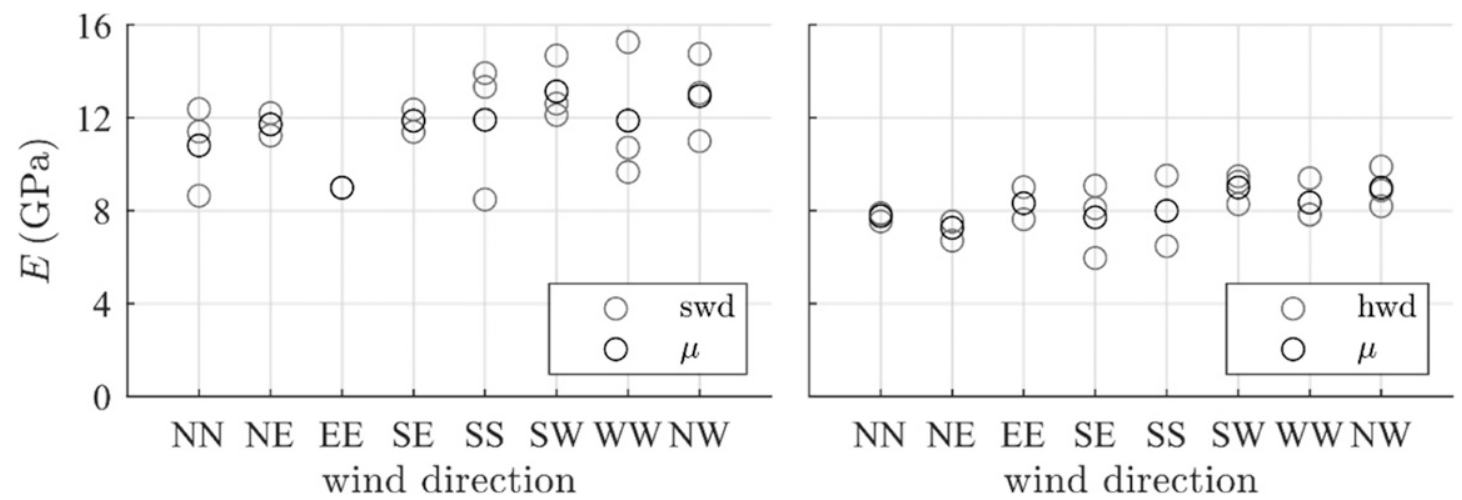

Figure 8. Raw data (gray) and mean values (black) for the elastic modulus $E$ obtained for the different wind directions (presented clockwise on the $\mathrm{x}$-axis) in the sapwood (swd) and heartwood (hwd) sample sets. 

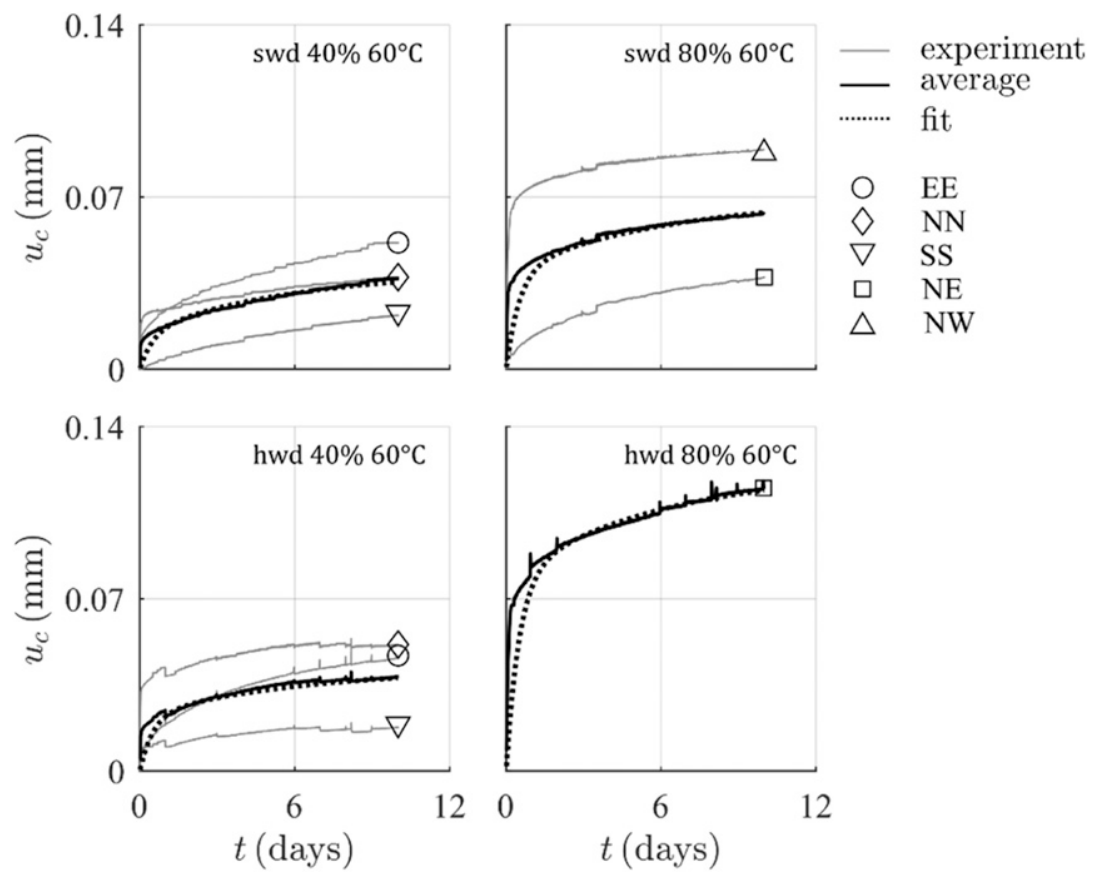

Figure 9. Individual and mean creep deflection curves $u_{c}$ obtained in the creep tests performed on $\log$ T1-3, together with a fit made with the 2-module Kelvin model.

creep deflection component $u_{c}$ of each specimen (from different locations in the log), the averaged curves, and a best fit based on Eq 8. Results of one sapwood and two heartwood specimens tested at $80 \% \mathrm{RH}$ could not be used because of LVDT failure. Despite the low variation in $E$ seen in the ST experiment, the results of each individual creep test show a noticeable variation in $u_{c}$ between specimens, which gives a mixed effect of position within the log and MC.

For sapwood, the averaged value of $u_{c}$ after $10 \mathrm{~d}$ of testing was $0.037 \mathrm{~mm}$ at $40 \% \mathrm{RH}$ and $0.063 \mathrm{~mm}$ at $80 \%$ RH. For heartwood, these values were $0.038 \mathrm{~mm}$ and $0.120 \mathrm{~mm}$, respectively. A $70 \%$ difference in $u_{c}$ for the all sapwood sets and a $200 \%$ difference for the all heartwood sets are observed when tests performed at $40 \% \mathrm{RH}$ and $80 \% \mathrm{RH}$ are compared. Table 3 summarizes the material parameters of Eqs 7 and 8 obtained with the fitting made with Eqs 7 and 8 fitted to the experimental data and the resulting $\chi_{w 0}$ parameter of Eq 12 used to express the moisture effect on each module of the Kelvin model.

\section{Change}

The changes in average MC (neglecting internal moisture gradients) in the reference sapwood and heartwood specimens labeled T1-2-WW during the LT experiment are presented in Fig 10. For both specimens, the MC fluctuated between 7\% and $13 \%$, which agrees with the EMC values published in 2010 FPL Wood Handbook: 6.3\% MC for $40 \% \mathrm{RH}$ and $13.6 \% \mathrm{MC}$ for $80 \% \mathrm{RH}$ (Wood Handbook 2010). The initial value for sapwood is $7.4 \%$ and for heartwood $7.7 \%$ at $40 \%$ $\mathrm{RH}$, and $12.8 \%$ and $12.7 \%$ at $80 \% \mathrm{RH}$, respectively. The MC at the FSP for $60^{\circ} \mathrm{C}$ calculated using Eq 10 was $23 \%$.

\section{Shrinkage and Swelling}

The hygro-expansion $u_{h}$ measured over the depth of the unloaded sapwood and heartwood reference specimens labeled T1-2-WW is presented in Fig 11, together with the hygro-expansion coefficient $\gamma$. Because of the RH cycle, $\gamma$ changes in 
Table 3. Creep parameters $\phi_{\sigma}^{n}$ and $\tau_{n}$ determined with the fit on the individual and average creep deflection curves using the 2-module Kelvin model, including the calculated values for $\chi_{w 0}$ for both sapwood and heartwood

\begin{tabular}{|c|c|c|c|c|c|c|}
\hline & \multirow{2}{*}{$\frac{\text { Moisture }}{w(\%)}$} & \multirow{2}{*}{$\frac{\text { Elastic }}{E^{*}(\mathrm{GPa})}$} & \multicolumn{4}{|c|}{ Creep } \\
\hline & & & $\phi_{\sigma}^{1}(-)$ & $\tau_{1}(\mathrm{~h})$ & $\phi_{\sigma}^{2}(-)$ & $\tau_{2}(\mathrm{~h})$ \\
\hline \multicolumn{7}{|l|}{ Sapwood } \\
\hline \multicolumn{7}{|l|}{$40 \% 60^{\circ} \mathrm{C}$} \\
\hline $\mathrm{EE}$ & 4.89 & 14.7 & 0.080 & 0.5 & 0.160 & 6.0 \\
\hline NN & 4.95 & 24.4 & 0.140 & 0.5 & 0.120 & 6.0 \\
\hline SS & 5.56 & 19.3 & 0.010 & 0.5 & 0.130 & 6.0 \\
\hline$\mu$ & 5.13 & 19.5 & 0.075 & 0.5 & 0.130 & 6.0 \\
\hline \multicolumn{7}{|l|}{$80 \% 60^{\circ} \mathrm{C}$} \\
\hline $\mathrm{NE}$ & 13.8 & 16.3 & 0.050 & 0.5 & 0.160 & 6.0 \\
\hline NW & 14.0 & 12.9 & 0.270 & 0.5 & 0.090 & 6.0 \\
\hline$\mu$ & 13.9 & 14.6 & 0.170 & 0.5 & 0.130 & 6.0 \\
\hline & - & - & 1.25 & - & 0.00 & - \\
\hline \multicolumn{7}{|l|}{$40 \% 60^{\circ} \mathrm{C}$} \\
\hline $\mathrm{EE}$ & 7.38 & 12.9 & 0.080 & 0.5 & 0.180 & 6.0 \\
\hline NN & 7.25 & 13.4 & 0.200 & 0.5 & 0.080 & 6.0 \\
\hline SS & 7.33 & 27.6 & 0.080 & 0.5 & 0.120 & 6.0 \\
\hline$\mu$ & 7.32 & 18.0 & 0.150 & - & 0.130 & - \\
\hline \multicolumn{7}{|l|}{$80 \% 60^{\circ} \mathrm{C}$} \\
\hline $\mathrm{NE}$ & 12.9 & 10.2 & 0.315 & 0.5 & 0.175 & 6.0 \\
\hline$\mu$ & 12.9 & 10.2 & 0.315 & - & 0.175 & - \\
\hline$\chi_{w 0}$ & - & - & 3.06 & - & 0.84 & - \\
\hline
\end{tabular}

value, and the values fluctuate slightly from cycle to cycle (Fig 11). Values between 0.39 and $0.35(-)$ are estimated for sapwood and between 0.17 and $0.09(-)$ for heartwood, of which the initial values of 0.39 and $0.17(-)$ found for sapwood and heartwood, respectively, correspond to values reported by Perstorper et al (2001) and Bengtsson (2001) for Norway spruce, where between pith and bark, an average is found around $0.35(-)$ and extremes between 0.18 and $0.5(-)$. The lower values for the heartwood specimen can be due to juvenile wood, which tends to experience a decrease in tangential hygro-expansion (Persson 2000). However, as mentioned previously, we were not able to determine the content of juvenile wood directly.

\section{Long-Term Experiment}

End-of-the-test criterion. Fig 12 shows the minimum (adsorption) and maximum (desorption) values of the total deflection $u_{t}$ recorded at
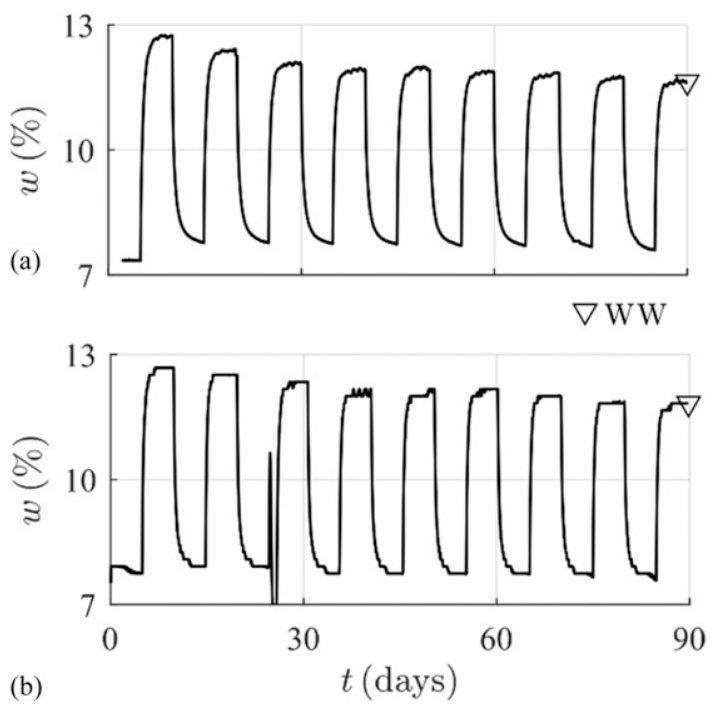

Figure 10. Average MC changes of the total volume before filtering for (a) sapwood and (b) heartwood specimen T1-2WW recorded during LT-tests.

the end of each half-cycle of the climate schedule for each specimen tested in the LT experiment with linear regression curves fitted to the last four extreme cycle points. The coefficient of determination $\left(R^{2}\right)$ for all lines exceeded 0.963, indicating that all beams reached a stage with constant deflection rate, the assumed criterion for the termination of the LT test. The regression lines are also shown in Fig 12.

Separation of the components of total deflection curves. The process of separation of the components of the total deflection of the test beams leading to the isolation of the mechanosorptive component is shown in Fig 13. The first set of curves (marked with a circle) represent the total deflection $u_{t}$ measured in the shear-free section of the beams subjected to LT load at variable climate conditions, separately for the sapwood and heartwood specimens. The part used in the analytical procedure is marked black. The recorded $u_{t}$ show characteristics similar to these first reported by Armstrong and Christensen (1961); Armstrong and Kingston (1962) for initially dry wood at relatively low load-level bending. The first adsorption (moisture intake) 

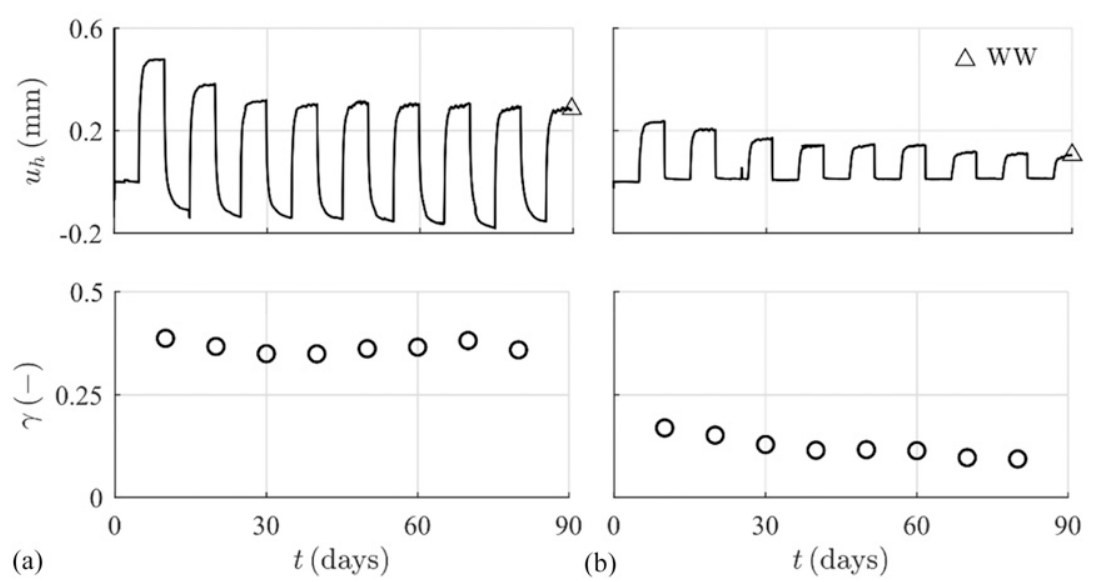

Figure 11. Hygro-expansion $u_{h}$ and swelling coefficient $\gamma$ obtained in the plane of loading (along the depth of specimen) for (a) sapwood and (b) heartwood specimen T1-2-WW tested in LT experiment.

and subsequent desorption (moisture release) result in substantial increase in deflection. When one neglects the fluctuation between high- and low-humidity cycles, a decreasing deflection rate in the first days of testing and a constant deflection rate for the remaining time are seen.

A wide range in $u_{t}$ is seen between the individual specimens of the all sapwood and all heartwood sample sets, highlighting the strong effect of the location within the log. When the load is chosen proportional to the mean $f_{b}$, this effect is more significant than the differences seen between sapwood and heartwood. The first graph in Fig 13(b) shows the early failure of specimen EE later traced back to the presence of a large knot with strong grain deviation around, despite the careful specimen selection procedure.

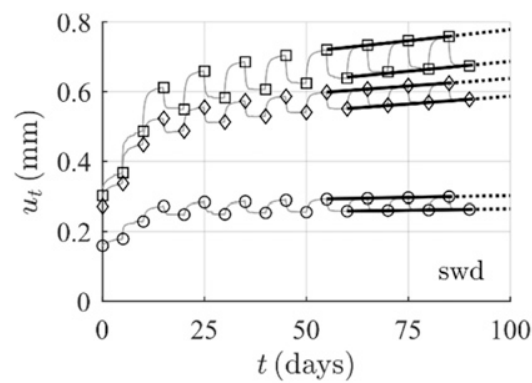

Looking at the individual deflection components, the $u_{m s}$ curves (marked with triangle) show a decreasing deflection rate, followed by a constant deflection rate. The $u_{e}$ curve (marked with diamond) is generally constant, showing a slight fluctuation change due to a difference in competing changes in $E(w)$ and modulus of inertia caused by cyclic moisture changes, leaving the resulting stiffness $E(w) I(w)$ almost unchanged. The tiny peaks in the curves are caused by a slight time difference between hygro-expansion and MC collected by different DAQ applications. For $u_{c}$, a decreasing deflection rate is found for the first $30 \mathrm{~d}$ of testing, after which no measurable growth is observed. This is in contrary to what is seen in Fig 9, where the creep curves show constant deformation rates at the end of the test. The series of Kelvin modules used to describe $u_{c}$

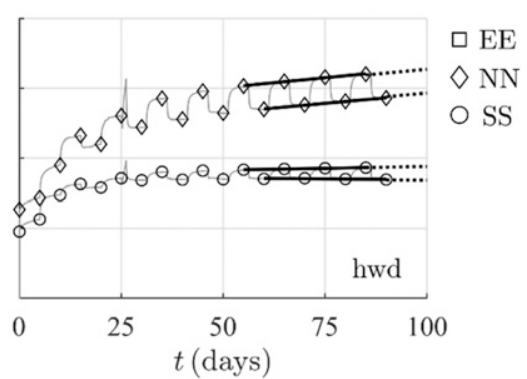

Figure 12. Analysis to determine the end of the long-term experiment based on linear regression lines for each specimen EE (squares), NN (diamonds), and SS (circles) in the sapwood (swd) and heartwood (hwd) sample sets. 

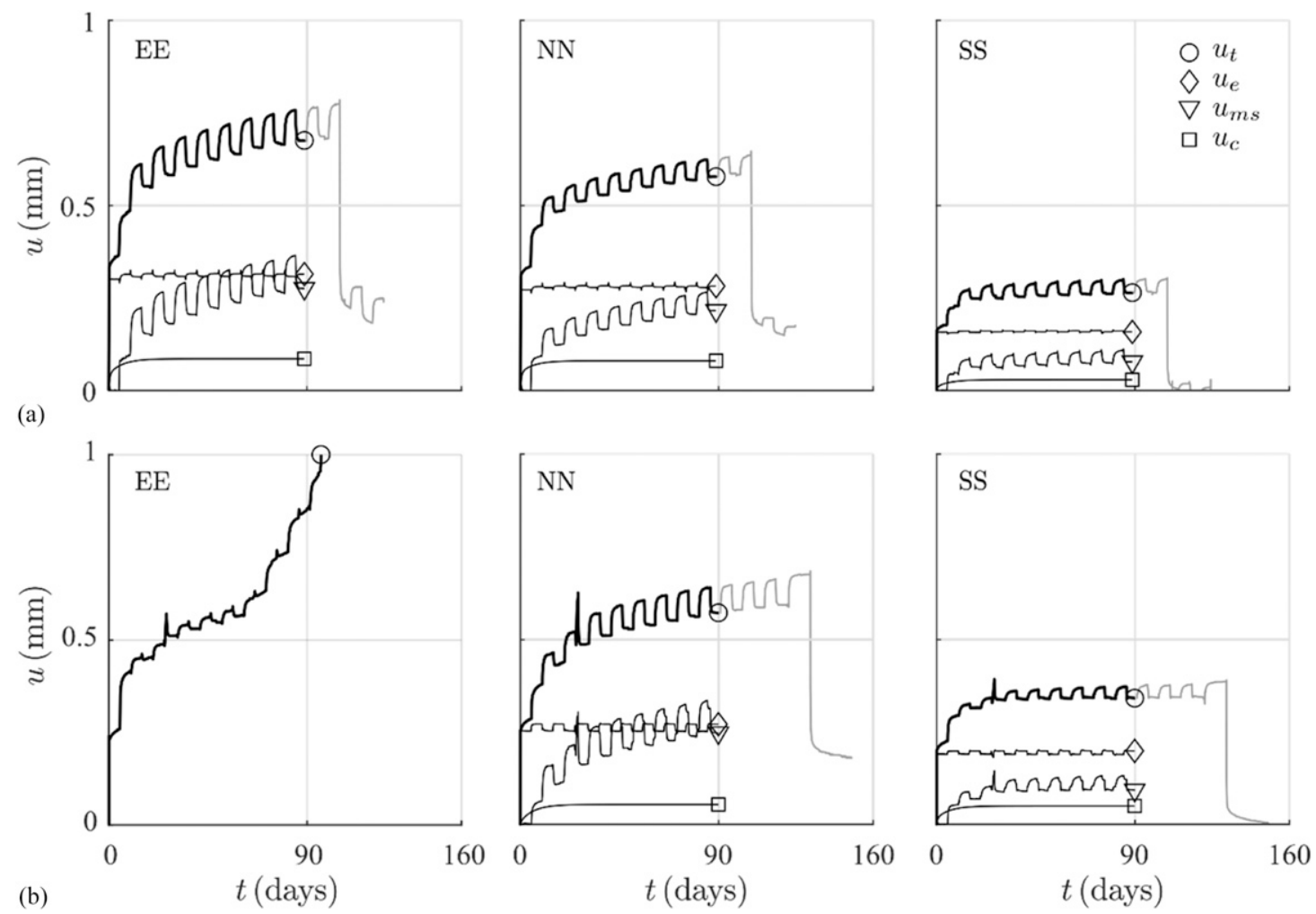

Figure 13. Separation of the total deflection $u_{t}$ curves into an elastic $u_{e}$, creep $u_{c}$, and mechano-sorptive $u_{m s}$ component for 90 da of LT tests (a) sapwood and (b) heartwood.

result in a good fit with the experimental data time range, but making it challenging to predict the behavior beyond the fit range because it will eventually trend toward a horizontal asymptote.

The largest contributor to $u_{t}$ measured in the shear-free section of the beam after $90 \mathrm{~d}$ of testing is $u_{e}(46-60 \%)$, followed by $u_{m s}(27-43 \%)$ and $u_{c}$ (10-15\%) (Table 4). This is consistent with observation made in the study on red spruce using a similar experimental methodology (Muszyński et al 2006). The values for $u_{c}$ are not negligible and prove essential for proper isolation of the mechano-sorptive deflection curve (Hering and Niemz 2012). With the chosen 2-module Kelvin model chain (see Eq 8), it is found that the $\mathrm{MC}$ at time of loading is more decisive for the magnitude of $u_{c}$ after $90 \mathrm{~d}$ of testing than the following $\mathrm{RH}$ cycles (see $u_{c, 40}, u_{c, 80}$, and $u_{c, 40-80}$ in Table 4). With the scale of these adjustments relatively small compared with the total creep deformation and the scale of other components, it was deemed safe to use the creep curve fit made at $40 \% \mathrm{RH}$ in the analysis. The parameters of Eq 11 obtained at loading and unloading at $80 \% \mathrm{RH}$ are collected in Table 5, together with the parameters of the 2-module Kelvin model chain fitted to $u_{c}$ obtained from the first $5 \mathrm{~d}$ of testing until the first climate cycle and corresponding to $80 \% \mathrm{RH}$ estimated with Eq 12.

The values for $E^{*}$ show a more distinct variation between specimens than previously seen in Fig 8 . The values found for $E^{*}$ and $E^{* *}$ do not show much difference between loading and unloading, both performed at the end of the $40 \% \mathrm{RH}$ part of the cycle. The creep parameters describing the initial deformation rate with the 2-module Kelvin model and collected in the creep tests (see Table 3) and the LT experiment (see Table 5) are 
Table 4. Total deflection $u_{t}$ at the end of 90-d tests in cycling climate conditions, compared with the values for the elastic $u_{e}$, creep $u_{c}$ and mechano-sorptive deflection $u_{m s}$ components calculated from the reference tests, including the elastic deflection right after loading $u_{e}^{*}$ and the percentage difference of each component with respect to $u_{t}$

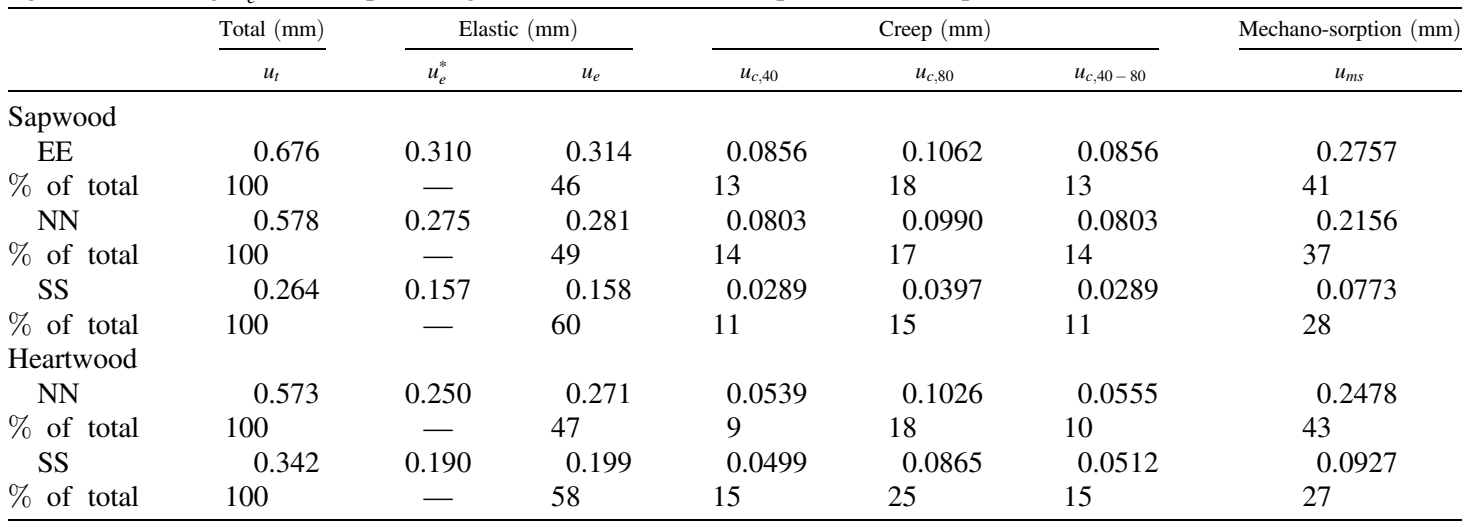

visualized in Fig 14 to show the effect of moisture on $\phi_{1}$ and $\phi_{2}$ and detect possible differences between the parameters obtained with the two tests. The effect of moisture is mainly seen in $\phi_{1}$, which is primarily used to describe the decreasing deflection rate, and complies with that in Table 4. No specific differences are found between the two test types.

\section{Analysis of the Mechano-Sorption Curves}

The mechano-sorptive deflection curves presented in Fig 15 in the cumulative MC domain develop in a similar manner as the strain curves presented for red spruce in tension parallel to the grain (Muszyński et al 2006). First, a decreasing deflection rate phase is experienced, followed by a constant deflection rate phase segment. The values of the fitted mechano-sorption parameters (used in Eq 9) are collected in Table 6 for each specimen tested in the LT experiment. A general difference observed between the data presented by Muszyński et al (2006) and Fig 15 is the presence of substantial oscillation that is clearly visible for the specimens tested in bending, which may be an effect of neglecting the internal moisture gradients within the specimens as they react to the rapid changes in the humidity of the ambient air between the $40 \%$ and $80 \%$ humidity.

In Table 6, the mechano-sorptive parameters belonging to each specimen tested in the LT experiment are collected. Because of the limited data sets, it is difficult to find a statistical correlation with a considerable confidence level

Table 5. Elastic modulus $E$ determined with the initial elastic deflection $(\bullet)^{*}$, unloading $(\bullet)^{* *}$ and Eq 11 at $80 \% \mathrm{RH}$, and creep parameters $\phi_{\sigma}^{n}$ and $\tau_{n}$ corresponding to the 2-module Kelvin model obtained from the first $5 \mathrm{~d}$ of testing under constant RH of $40 \%$ for each sapwood and heartwood specimens tested in the LT experiment, and estimated at $80 \%$ RH with Eq 12 and values for $\chi_{w 0}$ presented in Table 3

\begin{tabular}{|c|c|c|c|c|c|c|c|c|c|c|c|}
\hline & \multicolumn{3}{|c|}{ Elastic } & \multicolumn{8}{|c|}{ Creep } \\
\hline & $E^{*}(\mathrm{GPa})$ & $E^{* *}(\mathrm{GPa})$ & $E_{80}(\mathrm{GPa})$ & $\phi_{\sigma, 40}^{1}(-)$ & $\phi_{\sigma, 80}^{1}(-)$ & $\phi_{\sigma 0}^{1}(-)$ & $\tau_{1}(\mathrm{~h})$ & $\phi_{\sigma, 40}^{2}(-)$ & $\phi_{\sigma, 80}^{2}(-)$ & $\phi_{\sigma 0}^{2}(-)$ & $\tau_{2}(\mathrm{~h})$ \\
\hline \multicolumn{12}{|c|}{ Sapwood } \\
\hline EE & 12.2 & 12.6 & 11.0 & 0.140 & 0.207 & 0.33 & 0.5 & 0.120 & 0.120 & 0.14 & 6.0 \\
\hline NN & 13.8 & 12.9 & 12.6 & 0.170 & 0.237 & 0.36 & 0.5 & 0.120 & 0.120 & 0.12 & 6.0 \\
\hline SS & 25.7 & 25.6 & 24.5 & 0.060 & 0.127 & 0.25 & 0.5 & 0.120 & 0.120 & 0.12 & 6.0 \\
\hline \multicolumn{12}{|c|}{ Heartwood } \\
\hline NN & 11.3 & 11.6 & 10.2 & 0.086 & 0.237 & 0.48 & 0.5 & 0.176 & 0.217 & 0.31 & 6.0 \\
\hline SS & 15.3 & 13.4 & 14.3 & 0.026 & 0.177 & 0.54 & 0.5 & 0.186 & 0.227 & 0.30 & 6.0 \\
\hline
\end{tabular}



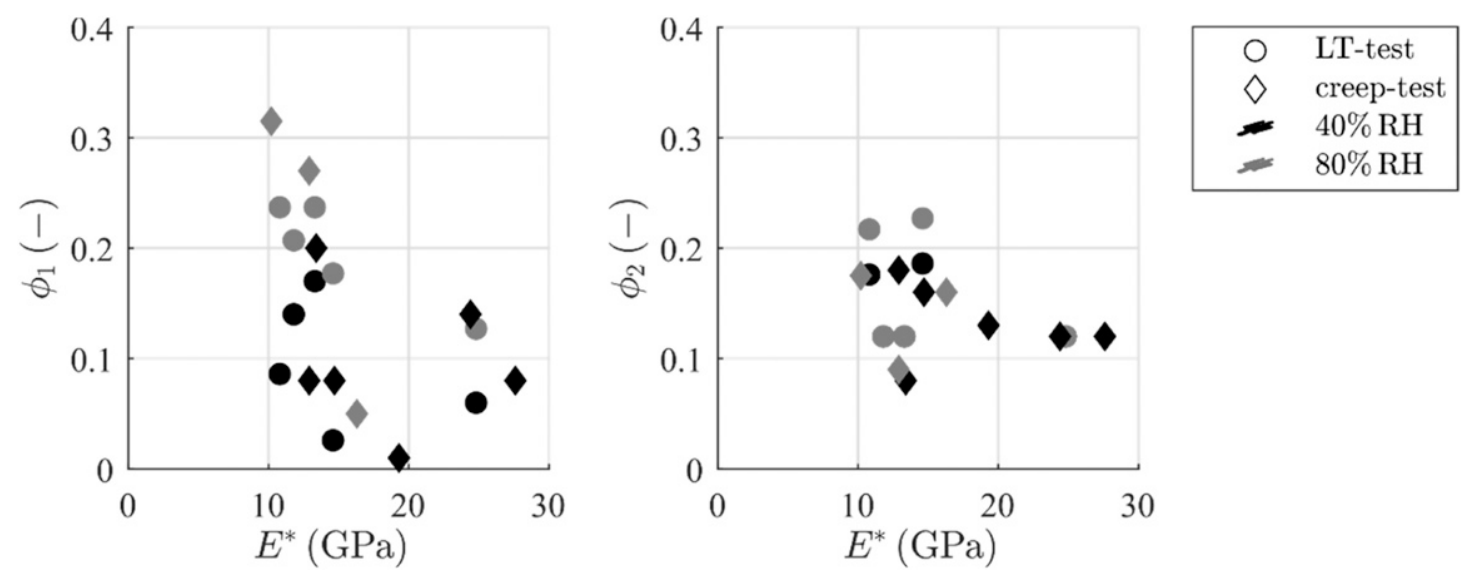

Figure 14. Initial deformation rate of the 2-module Kelvin model $\phi_{1}$ and $\phi_{2}$ obtained in the LT experiment (circles) and creep tests (diamonds) at 40\% (black) and $80 \%$ (gray) RH, previously presented in Tables 3 and 5 plotted against the elastic modulus at loading $E^{*}$.

between $E$, and $E_{m s}$ and $\alpha_{2}$. Also, it should be stressed again that it is inherently difficult to obtain reliable material-level mechano-sorptive characteristics because of the coincidence of internal moisture gradients, complex nonuniform stress patterns, and deviating material orientation (Muszyński et al 2005).

\section{CONCLUSIONS}

The purpose of the study is to provide the empirical validation to the beam element model developed by Ormarsson and Dahlblom (2013). The constitutive models similar to those used in that beam element model were used to extract the mechano-sorptive component of the total deflection by subtracting the moisture-dependent viscoelastic components.

The primary findings for the beam geometry presented in this article are as follows:

1. The experimental and analytical procedures led to a successful identification of each deflection component and isolation of mechano-sorptive deflection curves. The chosen constitutive model used to describe mechano-sorption allowed a reasonable fit and was able to describe both the

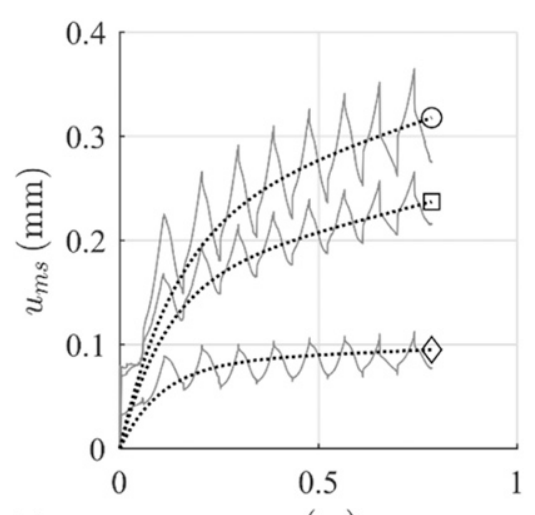

(a)

$$
v(-)
$$

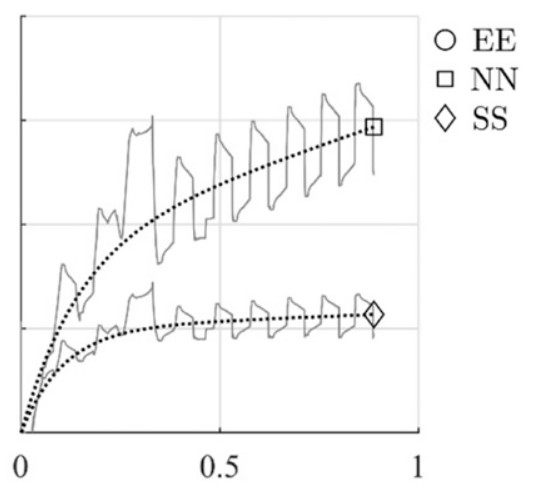

(b)

$$
v(-)
$$

Figure 15. Mechano-sorption deflection $u_{m s}$ component plotted in respect to cumulative MC change $v$ for each individual specimens part of (a) the sapwood and (b) the heartwood sample sets. 
Table 6. Mechano-sorptive model parameters $E_{m s}, \alpha_{1}$, and $\alpha_{2}$ obtained by fitting Eq 9 in the cumulative MC change domain $v$

\begin{tabular}{lccc}
\hline & \multicolumn{3}{c}{ Mechano-sorption } \\
\cline { 2 - 4 } & $E_{\mathrm{ms}}(\mathrm{MPa})$ & $\alpha_{1}\left(\mathrm{MPa}^{-1}\right)$ & $\alpha_{2}\left(\mathrm{MPa}^{-1}\right)$ \\
\hline Sapwood & & & \\
EE & 1.4 & 5.0 & 0.40 \\
NN & 1.7 & 5.0 & 0.35 \\
SS & 1.9 & 5.0 & 0.10 \\
Heartwood & & & \\
NN & 1.4 & 5.0 & 0.52 \\
SS & 1.9 & 5.0 & 0.08 \\
\hline
\end{tabular}

decreasing and constant deflection rate phases seen in the overall shape of the curves.

2. Over a period of $90 \mathrm{~d}$ of cyclic climate testing program, the elastic deflection was the most dominant component, followed by mechanosorption, and creep. Still, the creep deflection was nonnegligible and showed to be important for proper identification of the mechano-sorptive deflection component in the total deflection. The applied creep model gave good results over the period which was used to make the fit.

3. Although no considerable variation in the elastic modulus and modulus of rupture determined in static tests was found between specimens extracted from different positions in the $\operatorname{logs}$ (described by wind directions), the viscoelastic creep and mechano-sorptive deformations varied substantially. However, with just three specimens sourced from each position in the log, it is impossible to conclude on correlation. Nevertheless, we may conclude that in future projects, specimens should be grouped by end-matching along the grain.

4. The effect of moisture on creep behavior showed especially important during loading and the first stages of the decreasing deflection phase, after which the contribution decreased rapidly.

5. For the selected load level and range of cumulative moisture changes, no asymptotic limit of the mechano-sorptive deflection could be detected.

\section{FUTURE RESEARCH}

The quantities measured in this study will be used to validate the beam element model. MC, constitutive model parameters, and material characteristics are needed for the inputs, whereas total deflection and deflection components are needed for the outputs. To widen the range in which the beam model will be validated, additional tests at different temperatures and lower $\mathrm{RH}$ ranges should be performed. Also, to be able to make a statistical analysis, the number of specimens should be increased for each test.

\section{REFERENCES}

Armstrong LD, Christensen GN (1961) Influence of moisture changes on deformation of wood under stress. Nature 4791:869-870.

Armstrong LD, Kingston RST (1962) The effect of moisture content changes on the deformation of wood under stress. Aust J Appl Sci 13:257-276.

Bengtsson C (1999) Mechano-sorptive creep in wood: Experimental studies of the influence of material properties. Doctoral thesis, Chalmers University of Technology, Gothenburg, Sweden.

Bengtsson C (2001) Variation of moisture induced movements in Norway spruce (Picea abies). Ann Sci 58: 569-581.

Bodig J, Jayne BA (1982) Mechanics of wood and wood composites. Van Nostrand Reinhold Company, New York, NY.

Brancheriau L, Bailleres H, Guitard D (2002) Comparison between modulus of elasticity values calculated using 3 and 4 point bending tests on wooden samples. Wood Sci Technol 36:367-383.

Bratasz Ł, Kozłowska A, Kozłowski R (2012) Analysis of water adsorption by wood using the GuggenheimAnderson-de Boer equation. Eur J Wood Wood Prod 70:445-451.

Carlsson H, Thunell B (1975) Shrinking behaviour of wood during drying effect of tensile stresses. Paperi ja Puu, 7.

Castera P (1989) Tensile creep of small wood specimens across the grain under drying conditions. In IUFRO International Wood Drying Symposium, Seattle, WA.

Dinwoodie JM (1981) Timber: Its nature and behaviour, 2nd edition. E\&FN Spon Taylor \& Francis Group.

EN 13183-1 (2003) Moisture content of a piece of sawn timber Part 1: Determination by oven dry method. European Committee for Standardization (CEN), Brussels, Belgium.

EN 408 (2012) Structural timber - structural timber and glued laminated timber - determination of some physcial and mechanical properties. European Committee for Standardization (CEN), Brussels, Belgium.

Engelund ET, Salmen L (2012) Tensile creep and recovery of Norway spruce influenced by temperature and moisture. Holzforschung 66:959-965.

Hanhijärvi A (2000) Advances in the knowledge of the influence of moisture changes on the long-term mechanical performance of timber structures. Mater Struct 33:43-49. 
Hearmon RFS, Paton JM (1964) Moisture content changes and creep of wood. Forest Prod J 8:357-359.

Hering S, Niemz P (2012) Moisture-dependent, viscoelastic creep of European beech wood in longitudinal direction. Eur J Wood Wood Prod 70:667-670.

Holzer SM, Loferski JR, Dillard DA (1988) A review of creep in wood: Concepts relevant to develop long-term behavior predictions for wood structures. Wood Fiber Sci 21:376-392.

Hunt DG (1989) Linearity and non-linearity in mechanosorptive creep of softwood in compression and bending. Wood Sci Technol 23:323-333.

Hunt DG (1999) A unified approach to creep of wood. R Soc 455:4077-4095.

Keunecke D, Sonderegger W, Pereteanu K, Lüthi T, Niemz P (2007) Determination of Young's and shear moduli of common yew and Norway spruce by means of ultrasonic waves. Wood Sci Technol 41:309-327.

Lagaňa R, William GD, Muszyński L, Shaler SM (2011) Moment-curvature analysis of coupled bending and mechano sorptive response of red spruce beams. Wood Fiber Sci 43:280-292.

Morlier P (1994) Creep in timber structures Rilem report 8. Rilem Technical Committee, London, UK.

Muszyński L, Lagaňa R, Shaler SM (2006) Hygromechanical behavior of red spruce in tension parallel to the grain. Wood Fiber Sci 38:155-165.

Muszyński L, Lagaňa R, Shaler SM, Davids W (2005) Comments on the experimental methodology for determination of the hygro-mechanical properties of wood. Holzforschung 59:232-239.
Ormarsson S, Dahlblom O (2013) Finite element modelling of moisture related and visco-elastic deformations in inhomogeneous timber beams. Eng Struct 49:182-189.

Ormarsson S, Gíslason ÓV (2016) Moisture-induced stresses in glulam frames. Eur J Wood Wood Prod 74:307-318.

Ormarsson S, Steinnes JR (2014) An enhanced beam model for glued laminated structures that takes moisture, mechano-sorption and time effects into account. Paper Presented at the World Conference of Timber Engineering, August 10-14, 2014, Quebec, Canada.

Ottosen N, Petersson H (1992) Introduction to the finite element method. Prentice Hall, Lund, Sweden.

Persson K (2000) Micromechanical modelling of wood and fibre properties. Doctoral thesis, Lund University, Lund, Sweden.

Perstorper M, Johansson M, Kliger R, Johansson G (2001) Distortion of Norway spruce timber: Part I variation of relevant wood properties. Eur J Wood Wood Prod 59:94-103.

Ranta-Maunus A (1975) The viscoelasticity of wood at varying moisture content. Wood Sci Technol 9:189-205.

Risbrudt CD, Ritter MA, Wegner TH (2010) Wood handbook: Wood as an engineering material. Forest Product Laboratory, Madison, WI.

Rybarczyk W (1973) Study on the development of mathematical model of mechanical properties of some wood materials undergoing changes in their moisture conten (in Polish). Prace Instytutu Technologii Drewna 66(2):17-138.

Salin JG (1992) Numerical prediction of checking during timber drying and a new mechano-sorptive creep model. Eur J Wood Wood Prod 50:195-200. 


\begin{tabular}{|c|c|c|}
\hline \multicolumn{3}{|c|}{ Abbreviations } \\
\hline EMC & \multicolumn{2}{|c|}{ EMC } \\
\hline LT & \multicolumn{2}{|c|}{ Long-term, in reference to duration of tests and related specimens } \\
\hline ST & \multicolumn{2}{|c|}{ Static, in reference to the tests and related specimens } \\
\hline UTM & \multicolumn{2}{|c|}{ Universal testing machine } \\
\hline \multicolumn{3}{|c|}{ NOTATIONS and units } \\
\hline$a$ & $\mathrm{~mm}$ & Shear span (between load and support) \\
\hline$b$ & $\mathrm{~mm}$ & Width of specimen \\
\hline E & $\mathrm{MPa}$ & Pure elastic modulus \\
\hline$E_{m s}$ & $\mathrm{MPa}$ & $\begin{array}{l}\text { Parameter of mechano-sorptive model (analogue of } \\
\text { Hooke's spring parameter in Kelvin model) }\end{array}$ \\
\hline$Y_{w 0}$ & $\mathrm{MPa}$ & Term to indicate relation of $E$ to moisture \\
\hline$E_{0}$ & MPa & Reference value to describe $E$ \\
\hline$F$ & $\mathrm{kN}$ & Total bending load \\
\hline$f_{b}$ & $\mathrm{MPa}$ & Modulus of rupture (bending strength) \\
\hline$h$ & $\mathrm{~mm}$ & Depth of specimen \\
\hline$I$ & $\mathrm{~mm}^{4}$ & Moment of inertia \\
\hline$l_{d}$ & $\mathrm{~mm}$ & Gauge length for the determination of elastic modulus \\
\hline$l_{l}$ & $\mathrm{~mm}$ & Shear-free span (between loads) \\
\hline$l_{s}$ & $\mathrm{~mm}$ & Full span in bending \\
\hline$m$ & $\mathrm{~kg}$ & Mass \\
\hline$T$ & ${ }^{\circ} \mathrm{C}$ & Temperature \\
\hline$T_{0}$ & ${ }^{\circ} \mathrm{C}$ & Reference temperature of $20^{\circ} \mathrm{C}$ \\
\hline$u_{c}$ & $\mathrm{~mm}$ & Creep deflection component \\
\hline$u_{e}$ & $\mathrm{~mm}$ & Elastic deflection component \\
\hline$u_{g}$ & $\mathrm{~mm}$ & Deflection measured over the full span \\
\hline$u_{h}$ & $\mathrm{~mm}$ & Free hygro-expansion \\
\hline$u_{l}$ & $\mathrm{~mm}$ & Deflection measured in shear-free section beam, see $l_{d}$ \\
\hline$u_{m s}$ & $\mathrm{~mm}$ & Mechano-sorptive deflection component \\
\hline$u_{t}$ & $\mathrm{~mm}$ & Total deflection \\
\hline$v$ & - & Cumulative MC change \\
\hline$w$ & - & $\mathrm{MC}$ \\
\hline$w_{a}$ & - & MC below FSP \\
\hline$w_{f}$ & - & FSP \\
\hline$\alpha$ & $\mathrm{MPa}^{-1}$ & $\begin{array}{l}\text { Parameter of mechano-sorptive model (analogue of } \\
\text { dashpot viscosity in Kelvin model) }\end{array}$ \\
\hline$\gamma$ & - & Hygro-expansion coefficient \\
\hline$\varepsilon_{c}$ & - & Creep strain \\
\hline$\varepsilon_{e}$ & - & Elastic strain \\
\hline$\varepsilon_{h}$ & - & Free hygro-expansion strain \\
\hline$\varepsilon_{m s}$ & - & Mechano-sorption strain \\
\hline$\varepsilon_{t}$ & - & Total strain \\
\hline$\mu$ & - & Mean \\
\hline$\tau$ & $\mathrm{h}$ & Retardation time in Kelvin creep model \\
\hline$\phi_{\sigma}$ & - & Initial deformation rate in Kelvin creep model \\
\hline$\phi_{\sigma 0}$ & - & Reference term to describe $\phi_{\sigma}$ \\
\hline$\chi_{w 0}$ & - & Term to indicate relation of $\phi_{\sigma}$ to moisture \\
\hline$\psi_{\mathrm{fT}}$ & - & Term to describe relation of $w_{f}$ to temperature \\
\hline$\Delta$ & - & Range in reference to variables universal testing machine \\
\hline$(\bullet)^{*}$ & - & Material properties corresponding to loading stage \\
\hline$(\bullet)^{* *}$ & - & Material properties corresponding to unloading stage \\
\hline
\end{tabular}

